\title{
Propagating aleatory and epistemic uncertainty in land cover change prediction process
}

\author{
Ahlem Ferchichi ${ }^{\mathrm{a}}$, Wadii Boulila ${ }^{\mathrm{a}}$, Imed Riadh Farah ${ }^{\mathrm{a}}$ \\ ${ }^{a}$ RIADI Laboratory, National School of Computer Sciences, University of Manouba, Tunisia
}

\begin{abstract}
An objective of satellite remote sensing is to predict or characterize the land cover change (LCC) over time. Sometimes we are capable of describing the changes of land cover with a probability distribution. However, we need sufficient knowledge about the natural variability of these changes, which is not always possible. In general, uncertainties can be subdivided into aleatory and epistemic. The main problem is that classical probability theory does not make a clear distinction between aleatory and epistemic uncertainties in the way they are represented, i.e., both of them are described with a probability distribution. The aim of this paper is to propagate the aleatory and epistemic uncertainty associated with both input parameters (features extracted from satellite image object) and model structure of LCC prediction process using belief function theory. This will help reducing in a significant way the uncertainty about future changes of land cover. In this study, the changes prediction of land cover in Cairo region, Egypt for next 16 years (2030) is anticipated using multi-temporal Landsat TM5 satellite images in 1987 and 2014. The LCC prediction model results indicated that $15 \%$ of the agriculture and $6.5 \%$ of the desert will be urbanized in 2030 . We conclude that our method based on belief function theory has a potential to reduce uncertainty and improve the prediction accuracy and is applicable in LCC analysis.
\end{abstract}

Keywords: LCC prediction, aleatory-epistemic uncertainty, input parameters uncertainty, model structure uncertainty, parameter modeling, parameter estimation, correlation analysis, uncertainty propagation.

\section{Introduction and Review}

LCC is a central issue in the sustainability debate because of its wide range of environmental impacts. Models of LCC start with an initial land cover situation for a given case study area and use an inferred transition function, representing the processes of change, to simulate the expansion and contraction of a predefined set of land cover types over a given period. LCC models help to improve our understanding of the land system by establishing cause-effect relations and testing these on historic data. In this way they help to identify the drivers of LCC and their relative importance. In addition, the models can be used to explore future land cover pathways for different scenarios.

Constructing a LCC prediction model is not straightforward. The dynamic processes and feedback loops in the land cover system are complex and only partially understood. Therefore, the model structure is by definition a strong simplification of this system. In addition, the model parameter values are uncertain and the observations of the real system contain errors. These errors or uncertainties propagate through the model, which generates uncertainty in the modelled system state, i.e. in the land cover predictions. The land cover system behaves non-linearly through time, and therefore the uncertainty of the predictions is likely to be non-linear too. Thus, propagating uncertainty should be calculated iteratively.

During the past decade, there has been a growing research interest on modeling uncertainty related to LCC process. Several works has been conducted to address this issue such as: [1] [2] [3] [4]. The majority of these works agree 
that uncertainties should be classified into different types and treated accordingly. The most common distinction is to divide them into aleatory and epistemic uncertainties [5]. The former comes from the natural variability of a random event, while the latter represents a lack of knowledge. Aleatory uncertainty is often referred to as irreducible uncertainty because a better understanding of the natural phenomena cannot reduce it. On the contrary, improving our background knowledge can reduce our epistemic uncertainty; therefore, we call it reducible uncertainty.

The authors in [6] [7] [8] tend to converge to the conclusion that epistemic uncertainties (for example, lack of knowledge, incomplete information, or ambiguity) are different to aleatory uncertainties. Their main problem is that classical probability theory does not make a clear distinction between epistemic and aleatory uncertainties in the way they are represented, i.e., both of them are described with a probability distribution. Some fundamental issues that arise in remote sensing studies in the presence of both epistemic and aleatory uncertainties are as follows:

1. How to represent uncertainty about the LCC prediction process [1] [9].

2. How to represent model parameters and model structure uncertainty [1] [8] [10] [11] [12].

3. How to solve multidimensional problems [13] [14].

4. How to propagate uncertainty to a system level [1] [15] [16] [17].

5. How to make decisions under uncertainty [18].

Several alternative frameworks based on non-probabilistic theories have been proposed in the literature to try to answer these questions. By no means do the promoters of theories pretend to replace probability theory; they just present different levels of expressiveness that leave room for properly representing the lack of background knowledge [19]. The most common theories that are used from these alternatives are imprecise probabilities [20], random sets [21], belief function theory [22] [23], fuzzy sets [24] [25], and possibility theory [6] [8].

Nevertheless, some authors still argue that probability theory alone is enough to represent aleatory and epistemic uncertainty [6] [7] [8]. Moreover, they consider that the axioms of probability, including additivity, are a natural consequence of intuition, and a necessary condition to reason and make decision under uncertainty. In contrast, the non-probabilistic theories relax the additivity axiom. The use of theory of evidence in remote sensing is not new and has already given satisfactory results in various problems, like image fusion [26] [27] [28], change detection [23] [29], change prediction [9] [30] [31] [38], image segmentation [32] [33], or classification [22] [34] [35] [36] [37]. Some works use this theory in uncertainty propagation context [39] [40]. Abdallah et al. [39] used belief functions to propagate aleatory and epistemic uncertainties through climate change model. Zargar et al. [40] introduced an approach that uses belief function theory as a mathematical tool to represent and propagate uncertainty arising from snow water equivalent data sets.

The aim of this paper is to propagate aleatory and epistemic uncertainty associated with both input parameters (features representing object extracted from satellite image) and model structure of LCC prediction process using belief function theory. More precisely, the proposed approach is divided into six main steps: 1) parameter uncertainty identification step is used to identify the uncertain input parameters, their types of uncertainty (aleatory and/or epistemic), their sources of uncertainty, their reduction factors, and their correlations, according to study area and used data, 2) parameter modeling step is used to model and to transform all uncertain parameters in belief functions framework, 3) parameter estimation step based on confidence limits of Kolmogorov Smirnov is used to estimate the aleatory and epistemic input parameters, 4) parameter uncertainty propagation step is used to propagate aleatory and epistemic uncertainty of input parameters, 5) model structure modeling step is used to identify the types and the sources of uncertainty of model structure, and to model their uncertainty, and 6) model uncertainty propagation step is then used to propagate the uncertainty associated to model structure.

The article is outlined as follows. Section 2 introduces the theory of belief functions. Section 3 introduces the materials and the methods for the uncertainty propagation of LCC prediction process using belief function theory. Section 4 presents the experiment results. Finally, the conclusions are outlined in Section 5.

\section{Belief function theory}

Belief function theory, also called as evidence theory or Dempster-Shafer theory, was initially developed by Dempster [41] and formalized by Shafer [42]. This theory has the potential to quantify aleatory and epistemic uncertainty, and to solve multidimensional problems. In this section, the basic notations of the belief function theory are introduced. 


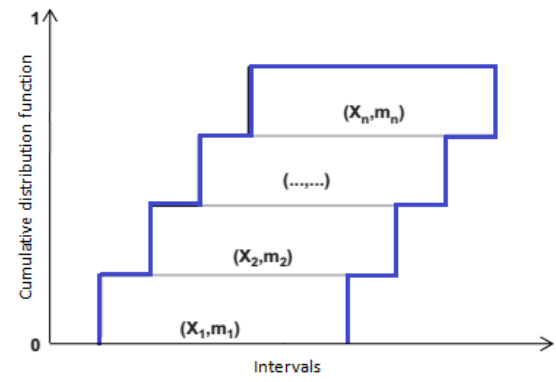

Figure 1. Evidence structure.

Frame of discernment (FD). The FD is defined by the finest possible subdivisions of the sets, and the finest possible subdivision is called the elementary proposition.

Basic Probability Assignment (BPA) and evidential measures. Belief function theory is based on two non-additive evidential measures: belief and plausibility, which can be estimated from BPA. The value of the BPA, also called mass, for a set $X_{i}$, represented as $m\left(X_{i}\right)$. The BPA is defined on a universal set $\mathrm{X}$ as a function of the power set $\Theta$ in the interval $[0,1]$ that satisfies three conditions: $m\left(X_{i}\right) \geq 0, m(\emptyset)=0$, and $\sum m\left(X_{i}\right)=1$. The measure of belief for a set $X_{i}, \operatorname{Bel}\left(X_{i}\right)$, represents the minimum belief in the claim that an element of the universal set $X$ belongs to the set $X_{i}$. The measure of plausibility for a set $X_{i}, P l\left(X_{i}\right)$, represents the maximum belief in the claim that an element of the universal set $X$ belongs to the set $X_{i}$, so $P l\left(X_{i}\right) \geq \operatorname{Bel}\left(X_{i}\right)$. Both $(B e l)$ and $(P l)$ play roles similar to distribution functions in the standard probability and they give the lower and upper bounds of the event. Evidential measures can be calculated from the BPA, for any set $X_{i}, X_{j} \in \Theta$ :

$$
\begin{aligned}
& \operatorname{Bel}\left(X_{i}\right)=\sum_{X_{j} \mid X_{j} \subseteq X_{i}} m\left(X_{j}\right) . \\
& \operatorname{Pl}\left(X_{i}\right)=\sum_{X_{j} \mid X_{j} \cap X_{i} \neq 0} m\left(X_{j}\right) .
\end{aligned}
$$

Evidence structures. If the focal elements: $\left(X_{1}, X_{2}, \ldots, X_{n}\right)$, are closed intervals: $\left(\left[A_{1}, B_{1}\right],\left[A_{2}, B_{2}\right], \ldots,\left[A_{n}, B_{n}\right]\right)$, then an evidence structure is defined as a collection of pairs formed by an interval and an associated mass $\left\{\left(X_{1}, m_{1}\right),\left(X_{2}, m_{2}\right)\right.$, $\left.\ldots,\left(X_{n}, m_{n}\right)\right\}=\left\{\left(\left[A_{1}, B_{1}\right], m_{1}\right),\left(\left[A_{2}, B_{2}\right], m_{2}\right), \ldots,\left(\left[A_{n}, B_{n}\right], m_{n}\right)\right\}$ where $A_{i} \leq B_{i}$ for all $i, B_{i} \neq B_{j}$ if $A_{i}=A_{j}$, and $\Sigma m_{i}=1$. Graphically, each of these pairs can be represented as a rectangle whose base corresponds to the interval $\left[A_{i}, B_{i}\right]$ located on the horizontal axis and whose height, on the ordinate axis, is equal to the mass or BPA associated, as shown in Figure 1.

\section{Materials and methods}

\subsection{Study area and data}

Cairo, the capital of Egypt, is one of the most crowded cities in Egypt (Fig. 2) and is considered a world megacity. Mapping LCC is important to understand and analyze the relationships between the geomorphology (highlands and deserts), natural resources (agricultural lands and the Nile River) and human activates. Agricultural lands around Cairo have witnessed severe encroachment practices due to the accelerated population growth. However, adjacent desert plains have also witnessed urbanization practices to encompass the intensive population growth. Different studies have previously been carried out for LCC detection and modeling in the Cairo Region [43] [44] [45] [46]. Population of Cairo (Cairo city and Giza) increased from about 6.4 millions in 1976 [43] to about 12.5 million in 2006 according to the Egyptian Central Agency for Public Mobilization and Statistics. The importance of Cairo arises from its location in the mid-way between the Nile Valley and the delta. Main government facilities and services occur at Cairo.

In this study, two Landsat TM5 satellite images were obtained from the United States Geological Survey (USGS) databases online resources. These two images acquired in 6 April 1987 and 15 March 2014, respectively, are classified 


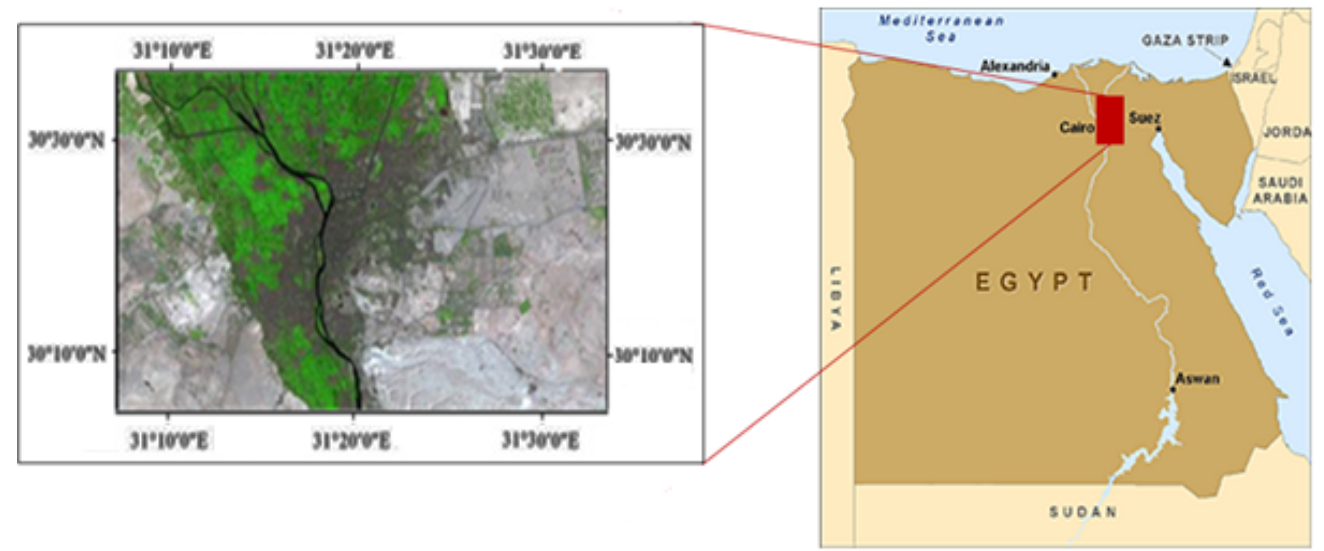

Figure 2. Location of the study area.

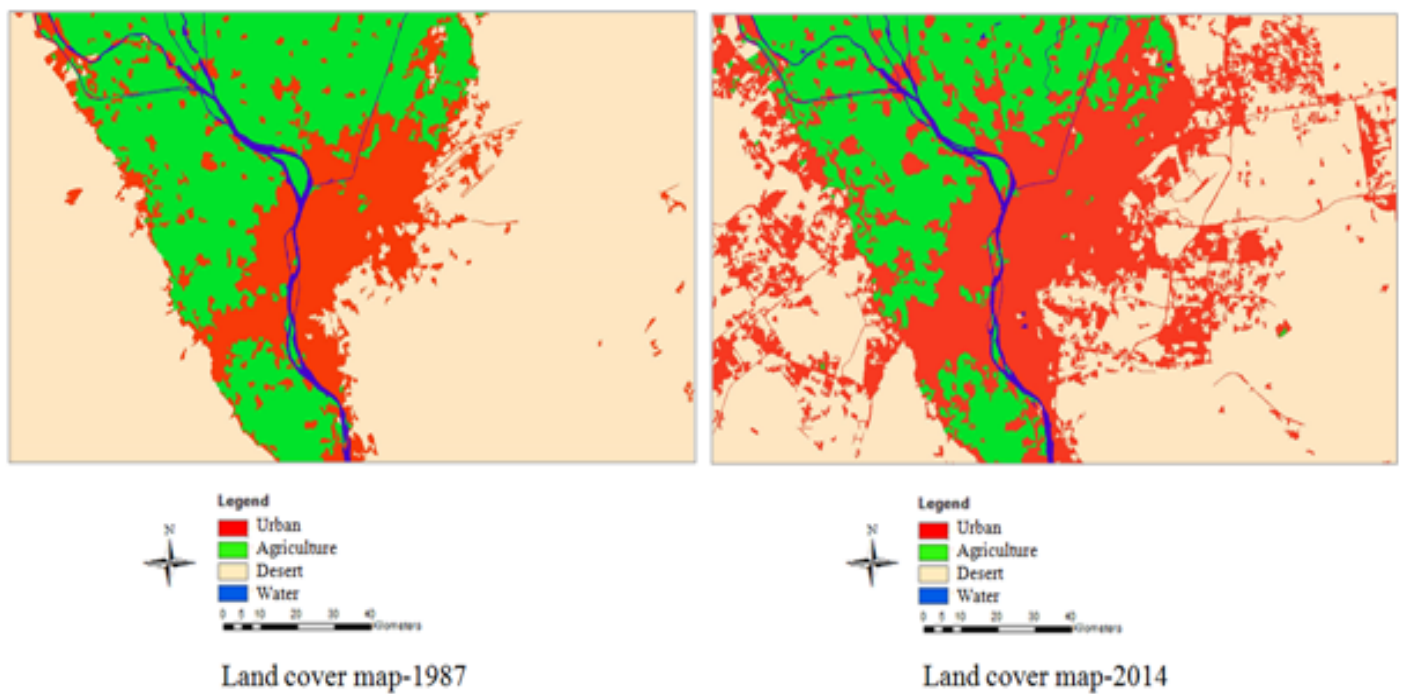

Figure 3. Land cover maps.

in four land cover types which are urban, agriculture, desert, and water to produce LCC maps (Fig. 3). During this time period, Cairo population has increased from an estimated 7 million in 1987 to over 15 million in 2014. The recent population growth has caused the city and its associated urban areas to expand into the surrounding desert, as seen in the second image (Fig. 3). Within the main Nile River Valley, these two images also show an overall increase in developed urban area (red) versus agricultural land (green). As new urban and agricultural areas are being developed in the desert, they require diversion of water supplies from the main Nile River Valley. In this study, satellite data were classified after initial corrections and processing in order to prepare the data for extracting useful information. Spectral, geometric, and atmospheric corrections of images were conducted to make features manifest, increase the quality of images and to eliminate the adverse effects of light and atmosphere.

\subsection{Methodology}

Predicting future changes may play a significant role in planning and optimal use of resources and harnessing the non-normative changes in the future. In literature, several models are proposed in order to predict LCC such as cellular automata models [47], markov chain model [48], logistic regression models [49], agent-based models [50], data mining models [51], and artificial neural networks [52]. In this paper, we apply the LCC model described by Qiang 


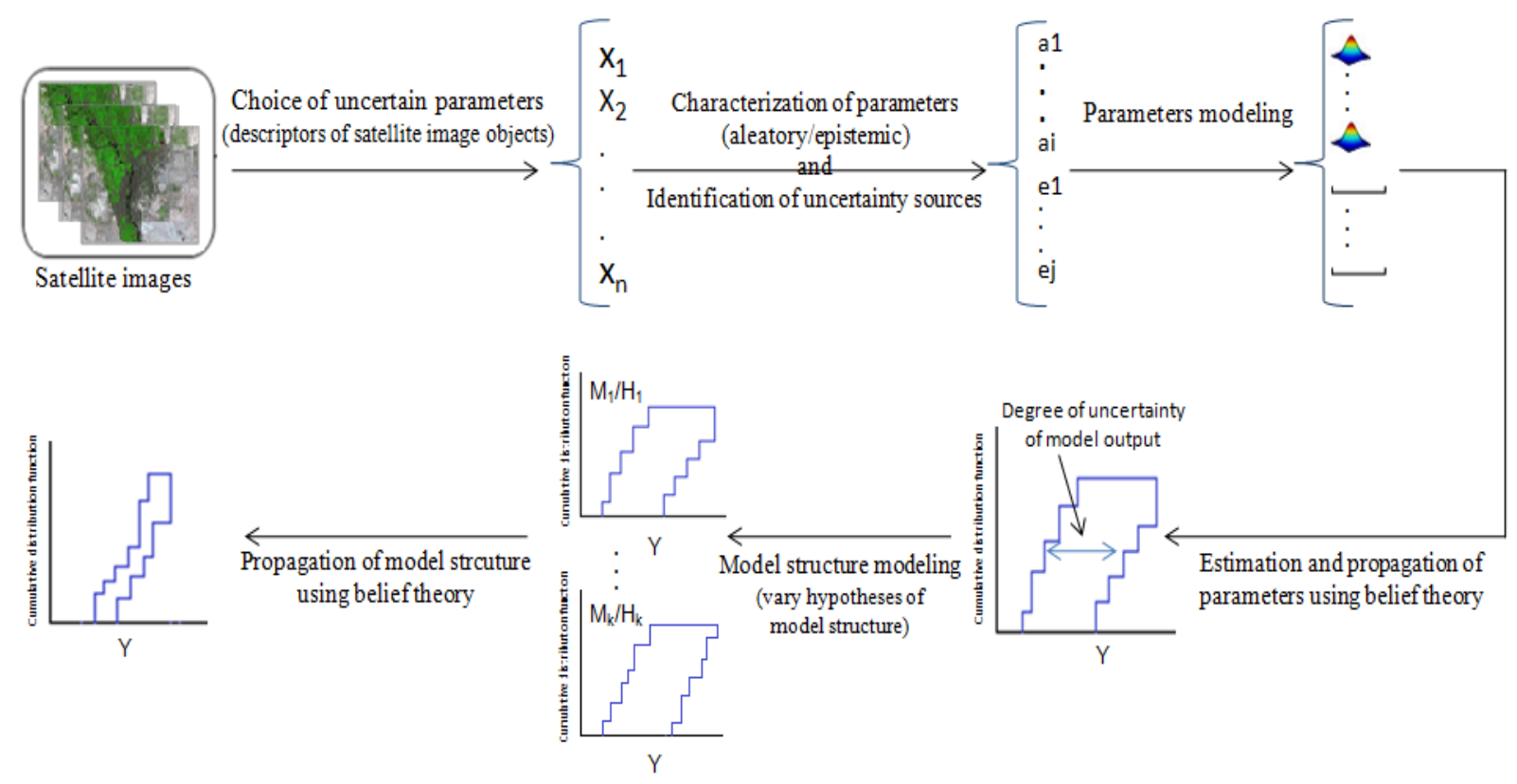

Figure 4. General modeling proposed framework.

and Lam in [53] to a Cairo region, Egypt. The advantages of using this model have been reported in the combining Cellular Automate (CA) model with Artificial Neural Network (ANN). CA are a type of discrete model commonly used in modeling spatial-temporal processes. They include five components: space, state, time step, neighborhood, and transitional rule. ANN are a type of modeling non-linear relations and now widely used for classification, pattern recognition, function approximation, and optimization in various applications. The LCC prediction model proposed in [53] used the ANN to derive the LCC rules, then, it used the CA model to simulate future scenarios. In general, input parameters (features extracted from satellite image objects) of LCC prediction model and the model structure (model itself) are marred by aleatory and epistemic uncertainties which affect the reliability of decision about these changes [1] [8] [9] [12]. Figure 4 illustrates the flowchart of the methodology applied during the study. This methodology follows four main steps:

1. identify the input parameters that can contribute to the uncertainty of model predictions, their types of uncertainty (aleatory and/or epistemic), their sources of uncertainty, their reduction factors, and their correlations, according to the study area and the used data;

2. model, estimate and propagate the aleatory and epistemic uncertainty associated to input parameters using belief functions theory;

3. identify types and sources of uncertainty of model structure and model their uncertainty;

4. propagate the uncertainty associated to model structure using belief functions theory.

\subsubsection{Step 1: Identifying model parameter}

Input parameters of LCC prediction model describe object features or descriptors extracted from satellite images and which are subject of studying changes. In this study, we extracted different features from Landsat TM5 satellite images by using five spectral, three texture, five shape, one vegetation, and two climate descriptors (Table 1). Spectral descriptors are: brightness index (BI) and mean values of blue (MB), red (MR), green (MG), and NIR (MN) bands for each image object. Texture descriptors are: contrast (Ctr), entropy (Ent), and angular second moment (ASM) generated from GLCM (Gray Level Co-occurrence Matrix). Shape and geometric descriptors are: rectangular fit (RF), elliptic fit (EF), shape index (SI), density (D), and area (A). Vegetation descriptor is: NDVI (Normalized Difference Vegetation Index) that is the ratio of the difference between NIR and red reflectance. Finally, climate descriptors are: temperature (Tem), and humidity (Hum). These parameters are used in this study to classify the different land cover 

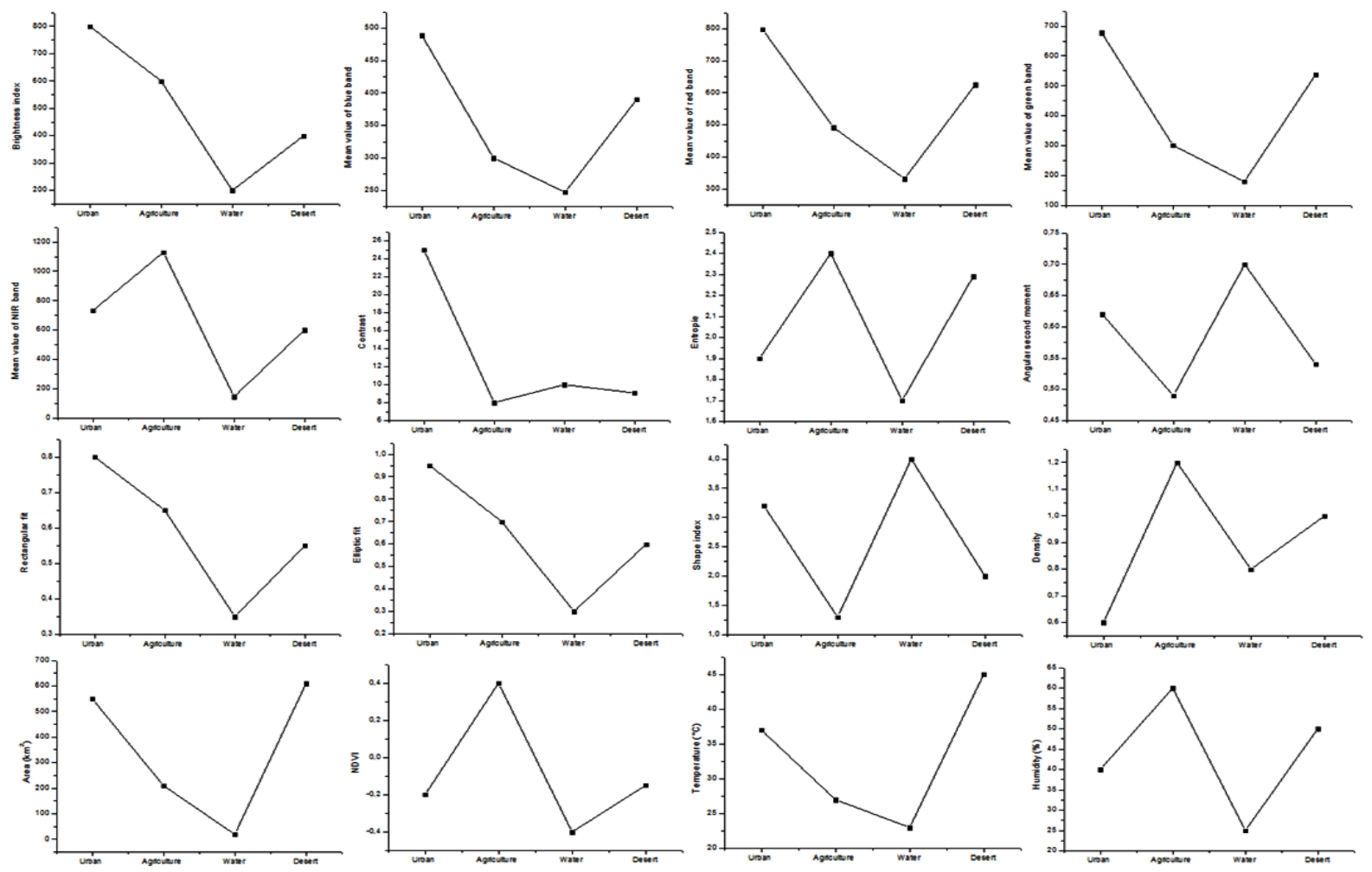

Figure 5. Values of input parameters in each land cover type.

types: urban, agriculture, desert, and water.

Figure 5 shows the values of input parameter of each land cover types according to the study area. Ideally, each value of these parameters should be accompanied by an uncertainty description. As we mentioned, uncertainties related to input parameters can be of two types: aleatory and epistemic. The type of uncertainty of each parameter depends on sources of their uncertainty. Therefore it is necessary to identify uncertainty sources that should be considered for processing. Table 2 shows the uncertain input parameters of LCC prediction model, their types, and their sources of uncertainty. In the current work, spectral, NDVI, and climate parameters are modeled as an aleatory uncertain variables described with normal probability distributions (mean and standard deviation values). Texture and shape parameters are modeled as epistemic uncertain variables because their uncertainty is due to the lack of knowledge in a physical model, and they are represented with intervals with specified bounds. Table 3 presents the uncertain values of both aleatory and epistemic parameters of each land cover type.

In the literature, several studies proposed some solutions (reduction factors) of uncertainty sources of input parameters. Table 4 shows these reduction factors. According to these factors, we can improve the quality of input parameters before their use in the uncertainty propagation step. We act on the distribution of each parameter to reduce their uncertainty sources. On the other hand, input parameters in remote sensing systems are not independent of each other. The value of one parameter can affect the value of another. LCC prediction models usually contain a large number of correlated parameters leading to non-identifiability problems. In this study, the Pearson correlation coefficient is used for analysis of linear correlation between input parameters of LCC prediction model. Table 5 shows values of correlation coefficient between input parameters.

\subsubsection{Step 2: Propagating model parameter uncertainty}

The objective of this step is to propagate aleatory and epistemic input parameters of LCC prediction model using belief function theory. The proposed approach takes advantages of the belief function theory to combine aleatory and epistemic mixed uncertainty in a very natural way. Belief function theory allows also considering correlation among 


\begin{tabular}{|c|c|c|c|}
\hline Parameters & Description & Formula & Range \\
\hline BI & $\begin{array}{l}\text { Brightness is the mean of gray values of all } \\
\text { bands for each pixel/segment. }\end{array}$ & $\frac{T M 1+\ldots+T M 7}{7}$ & $\begin{array}{l}{\left[C_{k}^{\min }, C_{k}^{\max }\right], C_{k}^{\min }: \text { darkest }} \\
\text { possible intensity value } \\
\text { and } C_{k}^{\text {max }}: \text { brightest possi- } \\
\text { ble intensity value }\end{array}$ \\
\hline $\mathrm{MB}$ & The mean value of blue spectral band. & - & {$\left[C_{k}^{\min }, C_{k}^{\max }\right]$} \\
\hline MR & The mean value of red spectral band. & - & {$\left[C_{k}^{\min }, C_{k}^{\max }\right]$} \\
\hline MG & The mean value of green spectral band. & - & {$\left[C_{k}^{\min }, C_{k}^{\max }\right]$} \\
\hline $\mathrm{MN}$ & $\begin{array}{l}\text { The mean value of near infrared spectral } \\
\text { band. }\end{array}$ & - & {$\left[C_{k}^{\min }, C_{k}^{\max }\right]$} \\
\hline $\mathrm{Ctr}$ & $\begin{array}{l}\text { The contrast is known as the "sum of } \\
\text { squares variance". }\end{array}$ & $\begin{array}{l}\sum_{i, j=0}^{N-1} P_{i, j}(i-j)^{2}, P_{i, j}: \text { the co- } \\
\text { occurrence matrix, } i \text { and } j: \text { the gray } \\
\text { levels, } N: \text { the number of gray levels }\end{array}$ & {$[0,90]$} \\
\hline Ent & $\begin{array}{l}\text { Quantifies the randomness of the gray-level } \\
\text { intensity distribution. }\end{array}$ & $\sum_{i, j=0}^{N-1}\left(-\ln P_{i, j}\right)$ & {$[0,90]$} \\
\hline ASM & Measures the textural uniformity. & $\sum_{i=0}^{N-1} \sum_{j=0}^{N-1} P(i, j)^{2}$ & {$[0,90]$} \\
\hline $\mathrm{RF}$ & Objects squareness & $\begin{array}{l}a / l_{\max } \times l_{\min }, \text { a: area of the polygon, } \\
l_{\max }: \text { length of the major axis, and } \\
l_{\min }: \text { length of the minor axis }\end{array}$ & {$[0,1]$} \\
\hline $\mathrm{EF}$ & Explains how will an object fits an ellipse. & - & {$[0,1]$} \\
\hline SI & $\begin{array}{l}\text { Shape index describes the smoothness of } \\
\text { the boundary of the object. }\end{array}$ & $\begin{array}{l}p /(4 \times \sqrt{a}), \mathrm{p}: \text { perimeter of the } \\
\text { polygon }\end{array}$ & {$[1, \infty]$} \\
\hline $\mathrm{D}$ & $\begin{array}{l}\text { The density is defined as the ratio between } \\
\text { the objects area and its radius, was used be- } \\
\text { cause human constructions [54]. }\end{array}$ & $\begin{array}{l}\sqrt{P_{v}} /\left(1+\sqrt{\sigma_{X}^{2}+\sigma_{Y}^{2}}\right), \sqrt{P_{v}} \text { : diame- } \\
\text { ter of a square object with } P_{v} \text { pixels, } \\
\text { and } \sqrt{\sigma_{X}^{2}+\sigma_{Y}^{2}} \text { : diameter of fitted } \\
\text { ellipse to the segment }\end{array}$ & $\begin{array}{l}{[0, \text { depending on the shape }} \\
\text { of image object }]\end{array}$ \\
\hline A & The area of the identified object. & - & {$[0$, scene size $]$} \\
\hline NDVI & $\begin{array}{l}\text { NDVI (Normalized Difference Vegetation } \\
\text { Index) is based on the principle of spectral } \\
\text { difference based on strong vegetation ab- } \\
\text { sorbance in the red and strong reflectance in } \\
\text { the near infrared part of the spectrum [55]. }\end{array}$ & $\frac{T M 4-T M 3}{T M 4+T M 3}$ & {$[-1,1]$} \\
\hline Tem & $\begin{array}{l}\text { Describes the degree of hotness or coldness } \\
\text { of an object. }\end{array}$ & - & $\mathbb{R}$ \\
\hline Hum & $\begin{array}{l}\text { The humidity is defined as the vapour pres- } \\
\text { sure deficit. }\end{array}$ & $\begin{array}{l}\frac{e}{e_{s}} \times 100 \%, e: \text { the actual water } \\
\text { vapour partial pressure, and } e_{s}: \text { the } \\
\text { saturated water vapour pressure }\end{array}$ & $\mathbb{R}$ \\
\hline
\end{tabular}

Table 1. Description, formula, and range of uncertain input parameters. 


\begin{tabular}{llll}
\hline Parameters & $\begin{array}{l}\text { Uncertainty } \\
\text { type }\end{array}$ & \multicolumn{1}{c}{ Uncertainty sources } & References \\
\hline \hline $\begin{array}{l}\text { Spectral } \\
\text { parameters }\end{array}$ & Aleatory & $\begin{array}{l}\text { Spectral reflectance of the surface, sensor calibration, sensor noise, ef- } \\
\text { fect of mixed pixels, effect of a shift in the channel location, pixel regis- } \\
\text { tration between several spectral channels, atmospheric temperature and } \\
\text { moisture profile, effect of haze particles, instrument's operation condi- } \\
\text { tions, atmospheric conditions, clouds, surface conditions that change } \\
\text { the target reflectance, topography, and viewing geometry. }\end{array}$ & [56] \\
\hline $\begin{array}{l}\text { Texture } \\
\text { parameters }\end{array}$ & Epistemic & $\begin{array}{l}\text { The spatial interaction between the size of the object in the scene and } \\
\text { the spatial resolution of the sensor, a border effect, and ambiguity in the } \\
\text { object/background distinction. }\end{array}$ \\
\hline $\begin{array}{l}\text { Shape } \\
\text { parameters }\end{array}$ & Epistemic & $\begin{array}{l}\text { Accounting for the seasonal position of the sun with respect to the Earth, } \\
\text { conditions in which the image was acquired changes in the scene's illu- } \\
\text { mination, atmospheric conditions, and observation geometry. }\end{array}$ \\
\hline $\begin{array}{l}\text { Vegetation } \\
\text { parameter }\end{array}$ & Aleatory & $\begin{array}{l}\text { Variation in the brightness of soil background, red and NIR bands, at- } \\
\text { mospheric perturbations, and variability in the structure of sub-pixel. }\end{array}$ \\
\hline $\begin{array}{l}\text { Climate } \\
\text { parameters }\end{array}$ & Aleatory & $\begin{array}{l}\text { Atmospheric correction, sensor noise, land surface emissivity, aerosols } \\
\text { and other gaseous absorbers, angular effects, wavelength uncertainty, } \\
\text { full-width half maximum of the sensor and band-pass effects. }\end{array}$ \\
\hline
\end{tabular}

Table 2. Types and sources of uncertainty of input parameters of LCC prediction model.

\begin{tabular}{r|cccc|cccc|cccc}
\hline Parameters & \multicolumn{5}{|c|}{ Mean } & \multicolumn{3}{|c|}{ Standard deviation } & \multicolumn{5}{c}{ Interval } \\
\hline & Urb & Agc & Wat & Dsr & Urb & Agc & Wat & Dsr & Urb & Agc & Wat & Dsr \\
\hline BI & 792 & 602 & 200 & 398 & 170 & 214 & 34 & 72 & - & - & - & - \\
MB & 489 & 301 & 247 & 390 & 173 & 21 & 16 & 70 & - & - & - & - \\
MR & 798 & 492 & 330 & 626 & 317 & 49 & 37 & 158 & - & - & - & \\
MG & 678 & 302 & 180 & 538 & 274 & 48 & 33 & 181 & - & - & - & - \\
MN & 733 & 1132 & 147 & 602 & 282 & 117 & 22 & 214 & - & - & - & - \\
Ctr & - & - & - & - & - & - & - & - & {$[24,26]$} & {$[7.5,9]$} & {$[9.5,10.5]$} & {$[8,8.5]$} \\
Ent & - & - & - & - & - & - & - & - & {$[1.7,2]$} & {$[2.2,2.5]$} & {$[1.5,2]$} & {$[2.25,2.3]$} \\
ASM & - & - & - & - & - & - & - & - & {$[0.6,0.65]$} & {$[0.47,0.5]$} & {$[0.7,0.75]$} & {$[0.5,0.55]$} \\
RF & - & - & - & - & - & - & - & - & {$[0.7,0.8]$} & {$[0.6,0.7]$} & {$[0.3,0.4]$} & {$[0.5,0.6]$} \\
EF & - & - & - & - & - & - & - & - & {$[0.9,1]$} & {$[0.6,0.7]$} & {$[0.2,0.3]$} & {$[0.4,0.5]$} \\
SI & - & - & - & - & - & - & - & - & {$[3,3.5]$} & {$[1,1.5]$} & {$[3.8,4.2]$} & {$[2,2.5]$} \\
D & - & - & - & - & - & - & - & - & {$[0.5,0.8]$} & {$[1,1.4]$} & {$[0.7,0.9]$} & {$[0.9,1.2]$} \\
A & - & - & - & - & - & - & - & - & {$[500,600]$} & {$[200,300]$} & {$[20,30]$} & {$[600,700]$} \\
NDVI & -0.19 & 0.43 & -0.2 & 0.28 & 0.13 & 0.26 & 0.25 & 0.20 & - & - & - & - \\
Tem & 36.48 & 28.4 & 26.5 & 42.8 & 1.9 & 0.8 & 1.7 & 0.83 & - & - & - & - \\
Hum & 39.18 & 60 & 25.5 & 49 & 1.02 & 1.9 & 1.7 & 0.8 & - & - & - & - \\
\hline
\end{tabular}

Table 3. Uncertain values of aleatory and epistemic parameters in land cover types (Urb: urban, Agc: agriculture, Wat: water, and Dsr: desert). 


\begin{tabular}{|c|c|c|}
\hline Parameters & Reduction factors of uncertainty & References \\
\hline $\begin{array}{l}\text { Spectral } \\
\text { parameters }\end{array}$ & $\begin{array}{l}\text { strict requirements for the instruments design, envisaging of appropriate procedures } \\
\text { for on-board calibration, choosing appropriate algorithms for radiometric and atmo- } \\
\text { spheric correction, reducing the wavelength range of the irradiance or spectral re- } \\
\text { sponse measurement, reducing the cloud shadows and cloud contamination effects } \\
\text { and reducing errors of sensor system itself. }\end{array}$ & [56] \\
\hline $\begin{array}{l}\text { Texture } \\
\text { parameters }\end{array}$ & using high spatial resolution and choosing appropriate methods for segmentation. & {$[58][59]$} \\
\hline $\begin{array}{l}\text { Shape } \\
\text { parameters }\end{array}$ & $\begin{array}{l}\text { improving platforms stability and carriers velocity, technological enhancement of the } \\
\text { sensors themselves, reducing effects of atmospheric conditions, improving the overall } \\
\text { segmentation quality, reducing the number of bad pixels and the size of bad areas, and } \\
\text { improvement of the uncertainty of pixels response. }\end{array}$ & [56] \\
\hline $\begin{array}{l}\text { Vegetation } \\
\text { parameter }\end{array}$ & $\begin{array}{l}\text { choosing appropriate algorithms for atmospheric correction, reducing errors in surface } \\
\text { measurements for the NIR and red bands, reducing temporal variations effects in the } \\
\text { solar zenith and azimuth angles, and reducing sun angle effects and noise contamina- } \\
\text { tion. }\end{array}$ & {$[60][61]$} \\
\hline $\begin{array}{l}\text { Climate } \\
\text { parameters }\end{array}$ & $\begin{array}{l}\text { choosing appropriate algorithms for atmospheric correction, reducing errors of sen- } \\
\text { sor system itself, reducing emissivity variations, reducing sun angle effects and solar } \\
\text { heating, reducing errors of radiometer calibration and errors of radiation, and reducing } \\
\text { errors of spatial and temporal variability of clouds. }\end{array}$ & {$[62][63]$} \\
\hline
\end{tabular}

Table 4. Reduction factors of uncertainty sources of input parameters of LCC prediction model.

\begin{tabular}{|c|c|c|c|c|c|c|c|c|c|c|c|c|c|c|c|c|}
\hline & BI & MB & MR & MG & $\mathrm{MN}$ & $\mathrm{Ctr}$ & Ent & ASM & $\mathrm{RF}$ & EF & SI & D & A & NDV & Tem & Hum \\
\hline BI & 1 & - & - & - & - & - & - & - & - & - & - & - & - & - & - & - \\
\hline MB & 0.98 & 1 & - & - & - & - & - & - & - & - & - & - & - & - & - & - \\
\hline MR & 0.99 & 0.96 & 1 & - & - & - & - & - & - & - & - & - & - & - & - & - \\
\hline MG & 0.98 & 0.94 & 0.95 & 1 & - & - & - & - & - & - & - & - & - & - & - & - \\
\hline $\mathrm{MN}$ & 0.98 & 0.95 & 0.95 & 0.98 & 1 & - & - & - & - & - & - & - & - & - & - & - \\
\hline $\mathrm{Ctr}$ & 0.25 & 0.85 & 0.83 & 0.81 & 0.79 & 1 & - & - & - & - & - & - & - & - & - & - \\
\hline Ent & 0.11 & 0.76 & 0.72 & 0.81 & 0.72 & 0.89 & 1 & - & - & - & - & - & - & - & - & - \\
\hline ASM & 0.29 & 0.85 & 0.83 & 0.87 & 0.79 & 0.97 & 0.98 & 1 & - & - & - & - & - & - & - & - \\
\hline RF & 0.12 & 0 & 0 & 0 & 0 & 0 & 0 & 0 & 1 & - & - & - & - & - & - & - \\
\hline $\mathrm{EF}$ & 0.18 & 0 & 0 & 0 & 0 & 0 & 0 & 0 & 0.99 & 1 & - & - & - & - & - & - \\
\hline SI & 0.26 & 0 & 0 & 0 & 0 & 0 & 0 & 0 & 0.89 & 0.90 & 1 & - & - & - & - & - \\
\hline $\mathrm{D}$ & 0.06 & 0 & 0 & 0 & 0 & 0 & 0 & 0 & 0.98 & 0.99 & 0.98 & 1 & - & - & - & - \\
\hline A & 0 & 0 & 0 & 0 & 0 & 0 & 0 & 0 & 0.76 & 0.76 & 0.78 & 0.76 & 1 & - & - & - \\
\hline NDVI & 0.82 & 0.65 & 0.71 & 0.98 & 0.98 & 0.32 & 0.28 & 0.32 & 0.01 & 0.01 & 0.01 & 0.11 & 0.21 & 1 & - & - \\
\hline Tem & 0.01 & 0 & 0 & 0 & 0 & 0 & 0 & 0 & 0 & 0 & 0 & 0.21 & 0 & 0.78 & 1 & - \\
\hline Hum & 0.08 & 0 & 0 & 0 & 0 & 0 & 0 & 0 & 0 & 0 & 0 & 0.02 & 0 & 0.81 & $\begin{array}{l}-0.8 \\
\end{array}$ & 1 \\
\hline
\end{tabular}


/ Ecological Informatics 00 (2016) 1-23

\begin{tabular}{rrrcrrcrr}
\hline \multicolumn{4}{c}{ Area } & \multicolumn{3}{c}{ NDVI } & \multicolumn{3}{c}{ Temperature } \\
\hline Interval & $B P A$ & $F(x)$ & Interval & $B P A$ & $F(x)$ & Interval & $B P A$ & $F(x)$ \\
\hline$[0,1200]$ & 0.04 & 0.04 & {$[-1,-0.5]$} & 0.5 & 0.5 & {$[0,10]$} & 0.05 & 0.05 \\
{$[1200,2400]$} & 0.09 & 0.13 & {$[-0.5,0]$} & 0.35 & 0.85 & {$[10,20]$} & 0.25 & 0.3 \\
{$[2400,3600]$} & 0.22 & 0.35 & {$[0,0.5]$} & 0.1 & 0.95 & {$[20,30]$} & 0.5 & 0.8 \\
{$[3600,4800]$} & 0.65 & 1 & {$[0.5,1]$} & 0.05 & 1 & {$[30,40]$} & 0.20 & 1 \\
Sum & 1 & & Sum & 1 & & Sum & 1 & \\
\hline
\end{tabular}

Table 6. Collection of interval-BPA pairs of area, NDVI, and temperature.

input parameters [13] for the LCC prediction process. For the proposed model, first we should identify which type of uncertainty is related to each input parameter. To explain the proposed method, let us consider a simple transfer function which has two uncertain parameters

$$
Y=f(e, a)
$$

where $e$ represents the epistemic uncertainty parameters (texture and shape parameters), $a$ represents the aleatory uncertainty parameters (spectral, NDVI, and climate parameters) and Y is the model response of the LCC prediction. For $e$, the epistemic uncertainty is generally expressed by a serie of subsets of the universal set associated with a BPA structure just as shown by the equation $\left\{\left[e_{1}^{L}, e_{1}^{U}\right] / m(1),\left[e_{2}^{L}, e_{2}^{U}\right] / m(2), \ldots,\left[e_{k}^{L}, e_{k}^{U}\right] / m(k), \ldots \mid k \in(1,2, \ldots, P)\right\}$. Where $P$ is the total number of subintervals of $e$ and $m(k)$ represents the BPA value associated with the $k^{\text {th }}$ subinterval $\left[e_{k}^{L}, e_{k}^{U}\right]$. When there are different BPA structures, we can use combining rule to integrate them into a combined BPA structure as $e_{j} / m\left(e_{j}\right)(j \in[1,2,, P])$ ultimately, where $e_{j}$ is also an interval as $\left[e_{j}^{L}, e_{j}^{U}\right]$ and $m\left(e_{j}\right)$ is the BPA value associated with the interval $e_{j}$. For $a$, assuming it has a normal distribution: $a \sim(\mu, \sigma)$, where $\mu$ is the mean and $\sigma$ is the standard deviation. The distribution scope can be truncated to $[\mu-\xi \sigma, \mu+\xi \sigma]$ approximately and then we can discretize the approximate interval into $N$ subintervals $\left[a_{i}^{L}, a_{i}^{U}\right], i \in[1,2, N]$, and for each subinterval the basic probability value is defined by the equation (4).

$$
m\left(a_{i}\right)=\int_{a_{i}^{L}}^{a_{i}^{U}} f(x) d x, i \in[1,2, \ldots, N] .
$$

where $a_{i}$ is defined as $\left\{a_{i} \mid x \in\left[a_{i}^{L}, a_{i}^{U}\right]\right\}$ and $f(x)$ is the probability density distribution function (pdf) of $x$. Obviously for the aleatory parameter, the equivalent BPA values within specified intervals are equal to the area under the pdf. After obtaining the BPA structures of all the uncertain parameters, we can estimate them with a certain level of confidence using confidence limits of Kolmogorov-Smirnov. To estimate the confidence intervals of Kolmogorov-Smirnov from the evidence structure, we use the expression proposed by Ferson et al. [66]:

$$
\operatorname{Min}(1, \max (0, F(x) \pm D(\alpha, n)))
$$

where $F(x)$ is the distribution function, $\alpha$ is the confidence level, and $D(\alpha, n)$ is the Kolmogorov statistic for a confidence level $100(1-\alpha) \%$ and a number $n$ of intervals. The values for $D(\alpha, n)$ were tabled by Miller [67] and were subsequently modified by Lilliefors [68]. For example, we construct the evidences structures of three parameters of urban object: area, NDVI, and temperature. For the latter, each interval in each parameter is treated as BPA. The collection of interval-mass pairs is created by associating these BPAs with each of the intervals in each parameter as shown in Table 6. The graphical representation of the evidence structures obtained of area, NDVI, and temperature is shown in Figure 6. According to the expression (5), confidence limits of Kolmogorov-Smirnov (using the modified values for $D(\alpha, n)$ by Lilliefors [68]) of these evidence structures for a confidence level of $95 \%$ ( $\alpha=95 \%)$, for 4 intervals, and for $D(\alpha, n)=0.381$ are shown in Table 7. Figure 7 shows these cumulative plausibility and belief functions together with the evidence structures. After obtaining the estimated BPA structures for all the uncertain parameters, we can integrate them into a joint structure. The joint BPA structure is defined by the Cartesian product [71]. In general, the cartesian product propagation method for evidence structures gives correct bounds on probability when propagating two variables with a completely unknown relationship. This is achieved by assuming that the first variable 

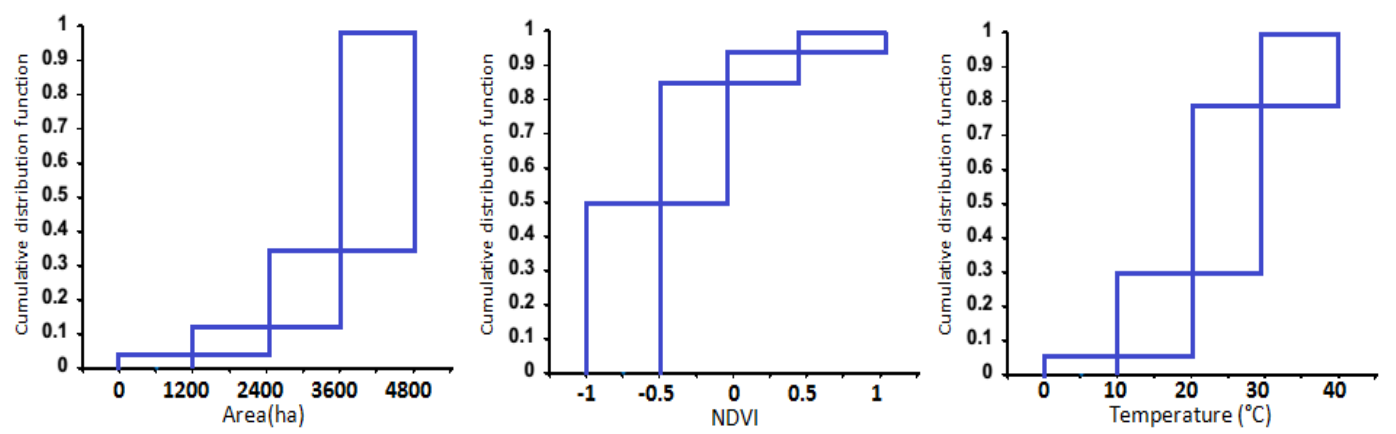

Figure 6. Evidence structures.

\begin{tabular}{rrrrrrrrrrrr}
\hline \multicolumn{4}{c}{ Area } & \multicolumn{1}{c}{ NDVI } & \multicolumn{4}{c}{ Temperature } \\
\hline Interval & $F(x)$ & Lower & Upper & Interval & $F(x)$ & Lower & Upper & Interval & $F(x)$ & Lower & Upper \\
\hline$[0,1200]$ & 0.04 & 0 & 0.421 & {$[-1,-0.5]$} & 0.5 & 0.119 & 0.881 & {$[0,10]$} & 0.05 & 0 & 0.431 \\
{$[1200,2400]$} & 0.13 & 0 & 0.511 & {$[-0.5,0]$} & 0.85 & 0.469 & 1.000 & {$[10,20]$} & 0.3 & 0 & 0.681 \\
{$[2400,3600]$} & 0.35 & 0 & 0.731 & {$[0,0.5]$} & 0.95 & 0.569 & 1.000 & {$[20,30]$} & 0.8 & 0.419 & 1.000 \\
{$[3600,4800]$} & 1 & 0.619 & 1.000 & {$[0.5,1]$} & 1 & 0.619 & 1.000 & {$[30,40]$} & 1 & 0.619 & 1.000 \\
\hline
\end{tabular}

Table 7. Confidence limits of Kolmogorov-Smirnov.
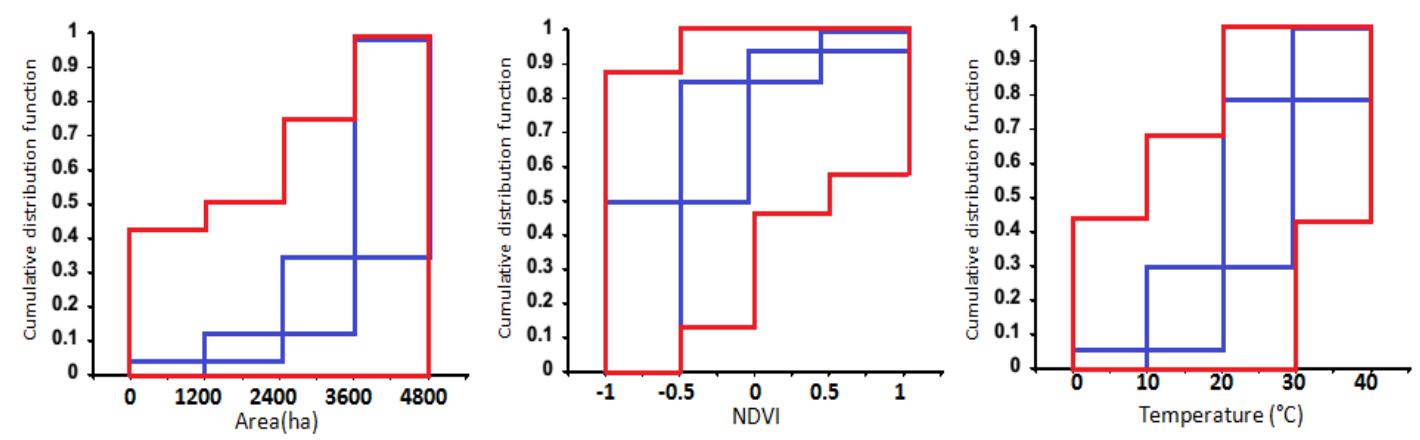

Unestimated evidence structures $\quad$ Estimated evidence structures

Figure 7. Evidence structures of area, NDVI, and temperature parameters. 
is set-uncertain and the second variable is represented using an evidence structure whose belief and plausibility values correspond to best-possible bounds on underlying probability. This method is synthesized as:

$$
C=a \times e=\left\{c_{i j}=a_{i} \times e_{j}\right\}
$$

where $C$ denotes the Cartesian set of all the uncertain parameters and $c_{i j}$ is the element of $C$.

- When the uncertain parameters, $e$ and $a$, are uncorrelated, the joint BPA for $c_{i j}$ is defined by multiplying the BPA of $a_{i}$ to the BPA of $e_{j}$.

$$
m\left(c_{i j}\right)=m\left(a_{i}\right) \times m\left(e_{j}\right)
$$

The focal element $c_{i j}$ is included by the joint FD, and its BPA is just equal to the multiplication of the corresponding marginal BPAs.

- When the uncertain parameters, e and a, are correlated, we will develop a new evidence theory model which takes into account the correlation among parameters based on ellipsoidal model [69] [72]. This model is originally proposed for non-probabilistic uncertainty analysis. In this paper, the ellipsoidal model is extended to deal with the correlated evidence parameters. For this purpose, a multidimensional ellipsoid is constructed by making all possible realizations of the $\mathrm{N}$-dimensional inter-correlated evidence parameters fall into a joint FD as shown by equation (8).

$$
\Omega=\left\{\mathbf{X} \mid\left(\mathbf{X}-\mathbf{X}^{c}\right)^{T} \mathbf{G}\left(\mathbf{X}-\mathbf{X}^{c}\right) \leq 1\right\}
$$

where the ellipsoidal center $\mathbf{X}^{c}$ is obtained through the marginal FDs as follows:

$$
X_{m}{ }^{c}=\frac{X_{m}{ }^{L}+X_{m}{ }^{R}}{2}, m=1,2, \ldots, N
$$

where $X_{m} \in c_{i j}$ are the evidence parameters (aleatory and epistemic parameters).

The symmetric positive-definite characteristic matrix $\mathbf{G}$ determines the size and orientation of the ellipsoid, reflecting the degree and the manner of correlation between the evidence parameters. Obviously, one should assign the belief probabilities only to the elements $c_{i j}$ that are partially or totally falling into the ellipsoid model. Thus, a joint BPA is formulated as:

$$
m\left(c_{i j} \cap \Omega\right)=\frac{m\left(a_{i}\right) \times m\left(e_{j}\right)}{S}, c_{i j} \cap \Omega \neq 0
$$

where $S$ is a normalization factor to make the total BPAs of $m$ equal to 1.0, which is given by

$$
S=\sum_{c_{i j} \cap \Omega \neq 0} m\left(c_{i j}\right)
$$

Then, minimum and maximum responses of each $c_{i j}$ are calculated by the equation (12).

$$
\left[Y_{\min }, Y_{\text {max }}\right]=\left[\min _{\mathbf{X} \in c_{i j}} f(\mathbf{X}), \max _{\mathbf{X} \in c_{i j}} f(\mathbf{X})\right]
$$

The Bel is obtained by summing all the joint BPA of element set $\mathbf{X}$, in which the maximal response $Y_{\max }$ is less than the limit state value $\left(Y_{\text {limit }}\right)$. The $P l$ is obtained by summing joint BPAs of these element sets, in which the $Y_{\text {limit }}$ is greater than the minimal response $Y_{\min }$.

\subsubsection{Step 3: Identifying model structure}

Models of LCC prediction are simplifications of reality; they are theoretical abstractions that represent systems in such a way that essential features crucial to the theory and its application are identified and highlighted [64]. LCC models are tools to support the analysis of the causes and consequences of LCC to support land-use planning and policy [65]. Models are useful for simplifying the complex suite of socioeconomic and biophysical forces that influence the estimation of changes [65]. Generally, each prediction model structure is represented by a number of hypotheses which are decisions or judgments considered by analysts. From a prediction model structure to another, the representations are different. Therefore it can keep uncertain representations. For example, when two hypotheses $H_{1}$, $H_{2}$ are given by two different experts, then we have two different structural models $M_{1}$ and $M_{2}$. The uncertainty related 


\begin{tabular}{l||l|l|l|l}
\hline & Urban & Agriculture & Water & Desert \\
\hline \hline Output of LCC prediction model & $15.00 \%$ & $11.20 \%$ & $0.01 \%$ & $3.80 \%$ \\
\hline Real changes in 2014 & $17.32 \%$ & $13.00 \%$ & $0.02 \%$ & $5.00 \%$ \\
\hline
\end{tabular}

Table 8. The output of LCC prediction model in comparison with the real changes between 1987 and 2014 in Cairo city.

to LCC prediction model structure is often neglected in the process of uncertainty treatment although according to Droguett and Mosleh [63] their impact on results was important and sometimes even more important than the impact of input parameters uncertainties. These impacts should therefore be taken into account in the final decision process. In most cases, uncertainty about LCC prediction model structure is a form of epistemic uncertainty because we are unsure whether their constructions are reasonable and complete. It would be aleatory uncertainty only if the structure of the governing model were itself to change over time, across space, or among components in some population.

\subsubsection{Step 4: Propagating model structure uncertainty}

The uncertainty propagation of model structure of LCC prediction is implemented in combination with the propagation of the input parameters uncertainty. In this section, as input parameters uncertainties are modeled by belief function theory, we use this technique in this framework. Suppose that a set of alternative models $M_{k}, 1 \leq k \leq K$ represents the uncertainty related to the choice of model. For each model $M_{k}$, uncertainty of input parameters is propagated through this model. Consequently, the output indicator $Y$ is characterized by a set of uncertainty representations according to each alternative model. Thus, for all alternative models $M_{k}, 1 \leq k \leq K$, we have a set of pairs of belief and plausibility functions for output variable $Y$, noted $\left\{\left[\operatorname{Bel}_{1}(Y), P l_{1}(Y)\right],\left[\operatorname{Bel}_{2}(Y), P l_{2}(Y)\right], \ldots,\left[\operatorname{Bel}_{K}(Y), P l_{K}(Y)\right]\right\}$. The difference between these representations reflects the variation associated to model structure uncertainty. These different representations $\left[\operatorname{Bel}_{i}(Y), P l_{i}(Y)\right], 1 \leq i \leq K$ can be combined into a single representation. Therefore, the final uncertainty representation of output variable $Y$ can be obtained by the following formulas.

$$
\begin{gathered}
\operatorname{Bel}^{*}(Y)=\min \left(\operatorname{Bel}_{1}(Y), \operatorname{Bel}_{2}(Y), \ldots, \operatorname{Bel}_{K}(Y)\right) \\
P l^{*}(Y)=\max \left(P l_{1}(Y), P_{2}(Y), \ldots, P l_{K}(Y)\right)
\end{gathered}
$$

Belief and plausibility functions $\left[\operatorname{Bel}^{*}(Y), P l^{*}(Y)\right]$ take into account both input parameters and model structure uncertainty in the final output result. The distance between $\mathrm{Bel}^{*}(Y)$ and $\mathrm{Pl}^{*}(Y)$ represents the degree of uncertainty or the effect of input parameters and model structure uncertainty of LCC prediction. In this study, this distance can be computed by the Kolmogorov-Smirnov (KS) distance [70]. The KS distance is a measure used in the statistical test [70] and is defined as the maximum difference between the sample CDF (cumulative distribution function) and the hypothesized CDF. This distance measures how close the sample CDF to the hypothesized CDF. In the proposed approach, we adopt the same idea to measure the difference between $\operatorname{Bel}^{*}(Y)$ and $\operatorname{Pl}^{*}(Y)$ distributions. The KS distance between these distributions is calculated as follows:

$$
\left.d_{K S}=\max _{Y}\left[P l^{*}(Y)\right]-\operatorname{Bel}^{*}(Y)\right]
$$

The equation implies that the KS distance is the maximum, discrepancy between two curves of $\mathrm{Bel}^{*}(Y)$ and $P l^{*}(Y)$.

\section{Experiment results}

The idea of this paper is to present an approach that reduces in a significant way the uncertainty about changes of land cover based on two land cover maps between 1987 and 2014 of Cairo region, Egypt (Fig. 3). As we indicated, we used the LCC prediction model described by Qiang and Lam in [53] to predict these changes. Table 8 shows the difference between predicted and real of LCC prediction model between 1987 and 2014 in Cairo region for each land cover type without uncertainty propagation.

Then, the aim of the experiment results section is to validate and to evaluate the performance of the proposed approach in propagating aleatory and epistemic uncertainty related to model parameter and model structure of LCC prediction. 


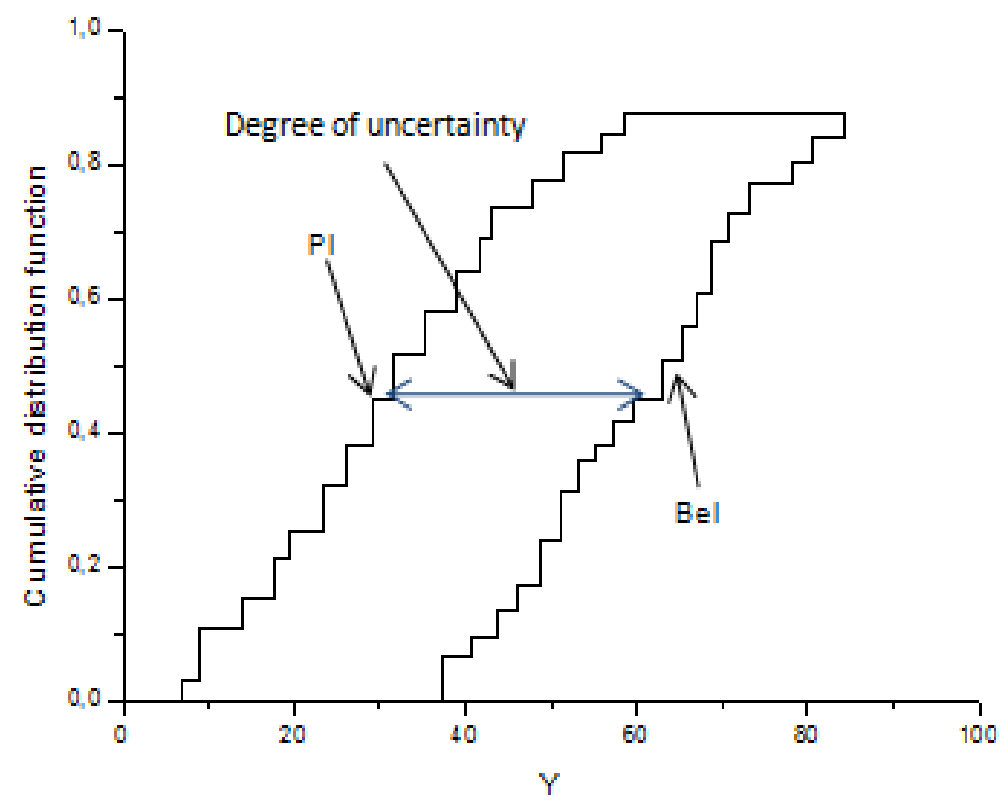

Figure 8. Output uncertainty of LCC prediction model represented by belief and plausibility distributions without uncertainty propagation.

\subsection{Results of uncertainty propagation}

Before the application of the proposed approach, we represent the output uncertainty of LCC prediction model with Bel and Pl distributions based on belief function theory, as shows Figure 8. This section is divided into two main steps: 1) Propagating model parameter uncertainty, and 2) Propagating model structure uncertainty.

\subsubsection{Propagating model parameter uncertainty}

As mentioned already, input parameters of LCC prediction model are marred by aleatory and epistemic uncertainty. Ignoring them can affect the results of uncerainty propagation. To illustrate the importance of propagating both uncertainty types through LCC prediction model, the analysis with pure aleatory uncertainty assumption is conducted where all 16 uncertain input parameters are treated as aleatory with normal probability distributions. In this case, the cumulative distribution function $(\mathrm{CDF})$ of output representing only the uncertainty in input parameters is obtained via belief function theory based on equation (12). In fact, Figure 9 shows this distribution based on 10,000 samples. Now, for both aleatory and epistemic uncertainty propagation of only input parameters in LCC prediction model, the specified bounds are used for the epistemic uncertain input parameters and the normal probability distributions are used for aleatory uncertain input parameters. The 10,000 samples are selected for both aleatory and epistemic cases. The CDF produced is shown in Figure 10.

As we have indicated also, input parameters of LCC prediction model are highly correlated. Then, it is necessary to study the effect of these correlated input parameters on output response variation and uncertainty propagation results. According to Pearson correlation coefficient, for example we found statistically significant correlations between the shape parameters (Table 5). Summarily, the shape index is significantly correlated with the Area, Density, rectangular fit, and elliptic fit. Moreover, we found statistically significant correlations between the NDVI parameter and climate parameters (Table 5). The NDVI parameter had a highest correlation with the temperature and humidity. Also, we note that the spectral parameters are correlated with texture parameters. Figure 11.b shows the distribution about the LCC when the correlation between input parameters is considered in comparison with the cumulative distribution of LCC when correlation between parameters is not taken into consideration in LCC prediction model (Fig. 11.a). Based on the proposed correlation approach (see equations 8, 9, and 10), the results show that there is not a big difference between the uncertainty propagation with and without concerning the nonlinear relation between parameters. However, it is important to distinguish the correlated and uncorrelated contribution of uncertainty for an individual parameter, 


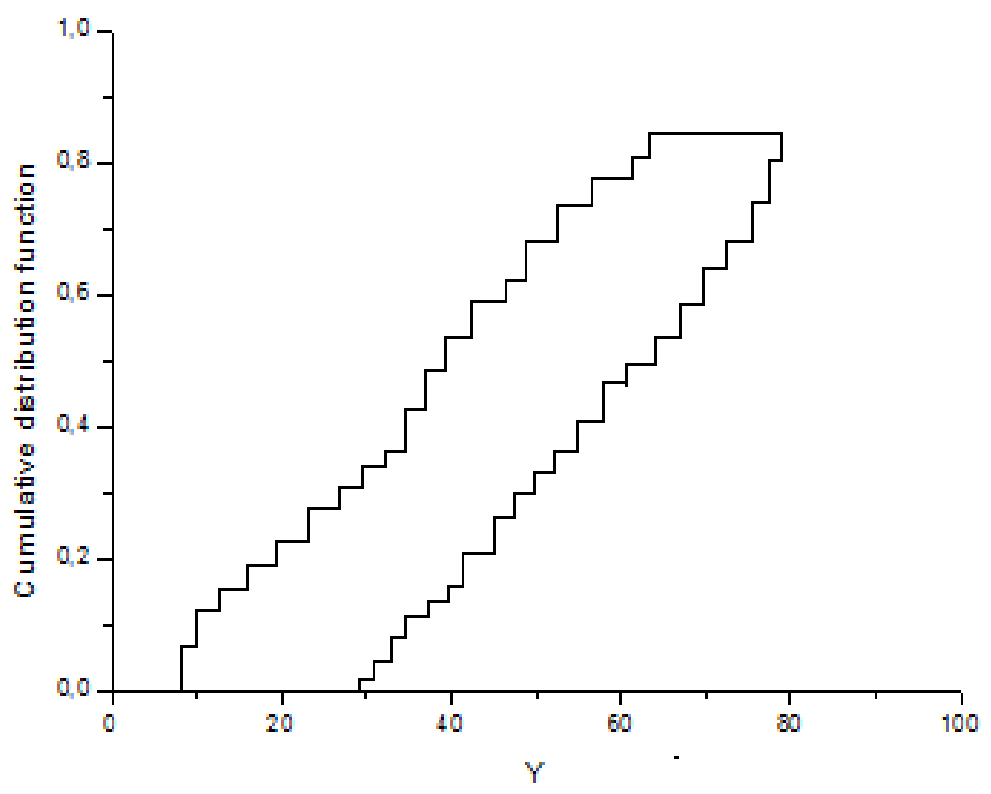

Figure 9. Output of LCC prediction model represented by belief and plausibility distributions with uncertainty propagation for only aleatory input parameters.

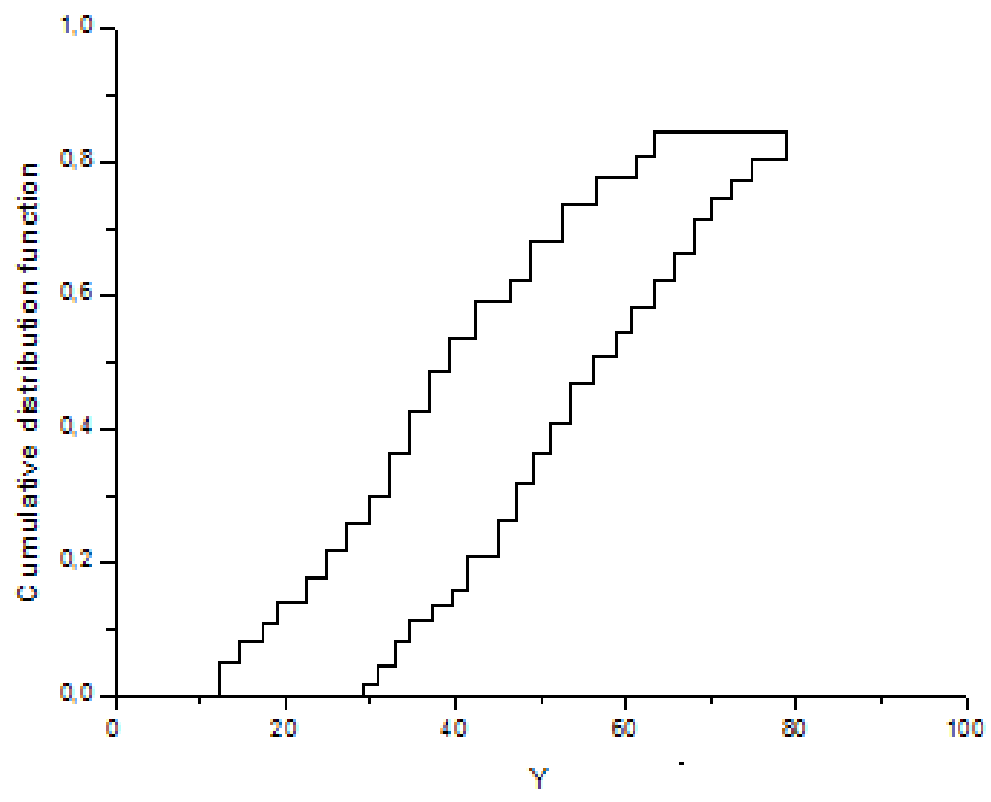

Figure 10. Output of LCC prediction model represented by belief and plausibility distributions with uncertainty propagation of both aleatory and epistemic input parameters. 


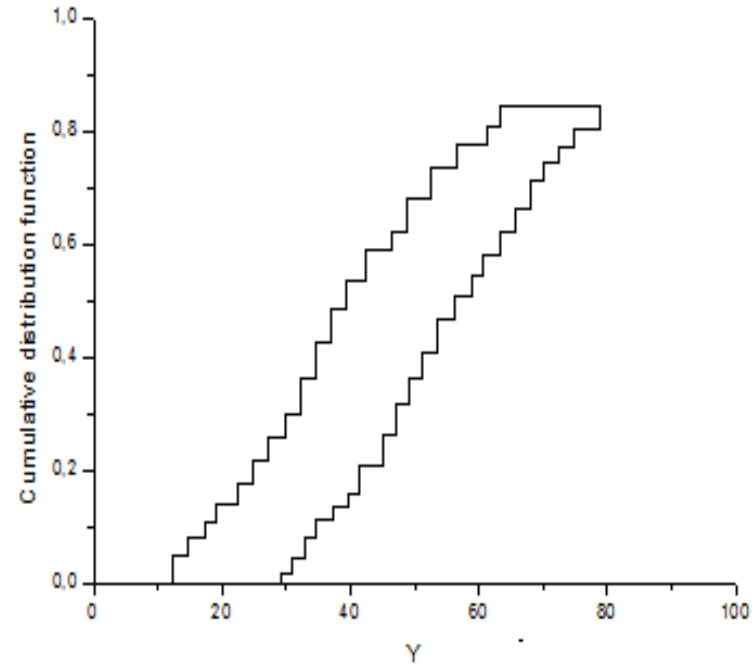

(a)

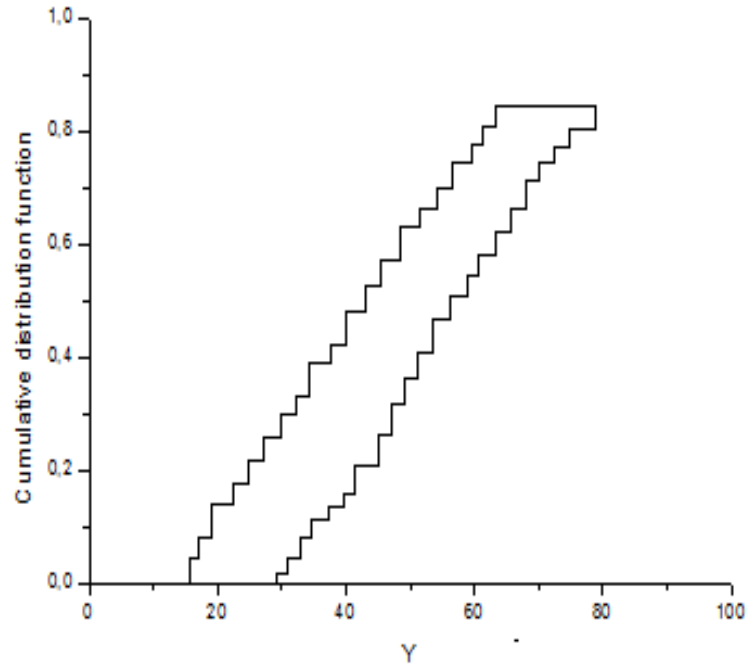

(b)

Figure 11. Output of LCC prediction model represented by belief and plausibility distributions: (a) 0utput of LCC prediction model represented by belief and plausibility distributions without considering correlations, and (b) Output of LCC prediction model represented by belief and plausibility distributions with considering correlations.

which would help engineers to decide if they need to focus on the correlated variations among specific parameters or the parameter itself.

\subsubsection{Propagating model structure uncertainty}

As we have indicated previously, in LCC prediction model, in addition to uncertainty in input parameters there is uncertainty in the model structure. Therefore, it is also significant to illustrate the importance of uncertainty in model structure using the proposed approach. This is the reason why we used the LCC prediction model described by Qiang and Lam in [53] with three different hypotheses. Then, we have three different models such as $M_{1} / H_{1}$, $M_{2} / H_{2}$, and $M_{3} / H_{3}$. Thus, to take into account the uncertainty related to model structure in the final result, for each prediction model, uncertainties associated with input parameters are first propagated. Figure 11 shows the result of the belief and plausibility functions of the LCC prediction model where only input parameters uncertainty is propagated. After the propagation of uncertainty of input parameters through three different model structures, we have three uncertain representations of LCC, which are shown in Figure 12. The difference between these three representations presents the impact of uncertainty of model structure. Compared with the result of the original LCC prediction model $\left(M_{1} / H_{1}\right)$, we can see that, this difference is important. Note that the obtained results are very similar because we have not used very different assumptions compared to the original ones. Propagation of uncertainties of the different model structures gives insights in the contribution of these structures to output variable. The assessment of the propagation of uncertainties enables the identification of the structures with the highest priority for improvement given the aim of the end user. Figure 13 shows belief and plausibility functions representing integrated input parameters and model structure uncertainties about the LCC. Note that the combined effect of model structure and input parameters uncertainty lead to a wider uncertainty bound of the LCC when compared against the case of uncertainties related to input parameters (Fig. 11.b). Also, the most probable value for the LCC when only input parameters uncertainty is taken into account is considerably lower than in the combined case, indicating an underestimation of the LCC.

We conclude that the uncertainty propagation demonstrated in this paper has the ability to reduce the uncertainty in land cover predictions and can help to guide users what such analysis can and cannot be used for.

\subsection{Results of LCC prediction maps}

The validation of LCC prediction maps consists of two phases. First, the 2014 LCC is simulated using the 1987 datasets, which is then compared with the real LCC in 2014 to evaluate the accuracy and the performance of the 


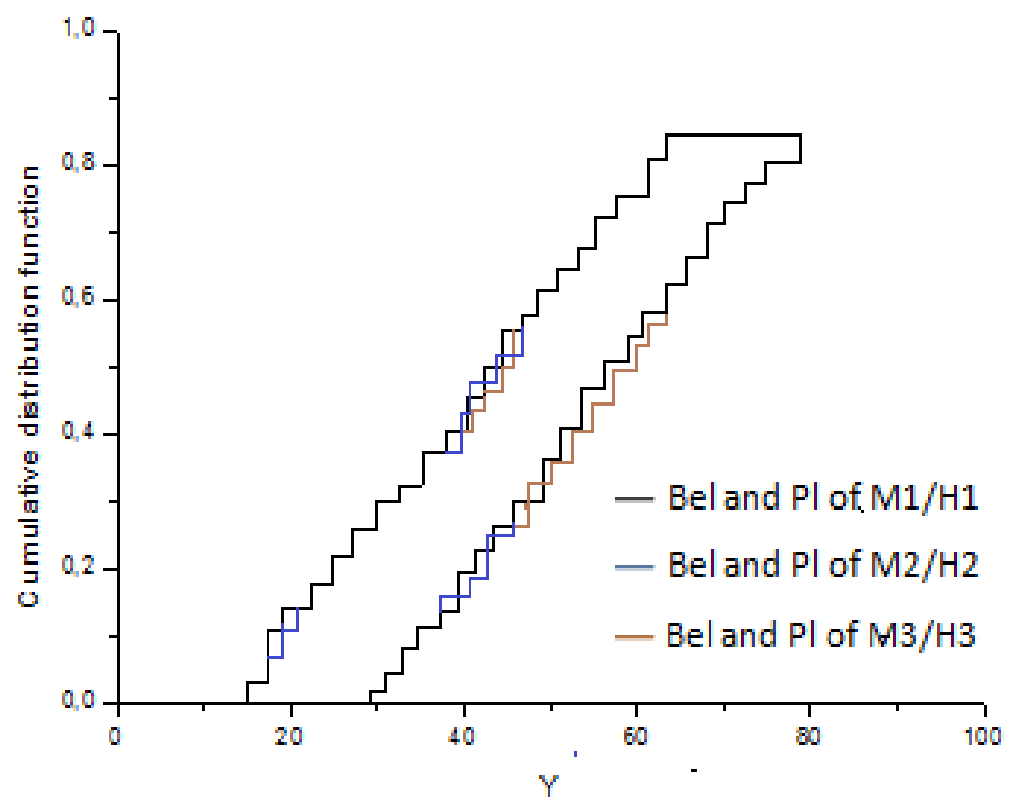

Figure 12. Belief and plausibility functions of LCC for three different prediction model structures.

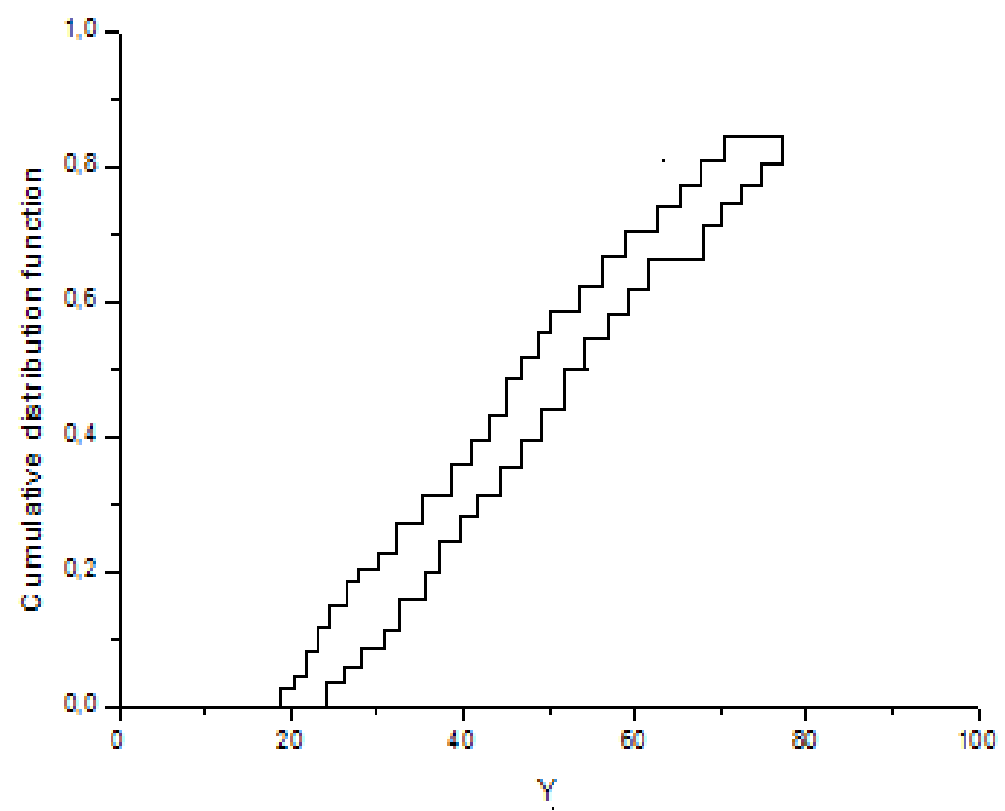

Figure 13. Belief and plausibility functions of the combined input parameters and model structure uncertainty for LCCs. 


\begin{tabular}{l||l|l|l|l}
\hline & Urban & Agriculture & Water & Desert \\
\hline \hline Output of proposed model & $16.01 \%$ & $12.00 \%$ & $0.02 \%$ & $4.20 \%$ \\
\hline Real changes in 2014 & $17.32 \%$ & $13.00 \%$ & $0.02 \%$ & $5.00 \%$ \\
\hline
\end{tabular}

Table 9. Output of the proposed LCC prediction model in comparison with real changes between 1987 and 2014 in Cairo region.

\begin{tabular}{l||l|l|l|l}
\hline & Urban & Agriculture & Water & Desert \\
\hline \hline Predicted changes in 2030 & $21.93 \%$ & $15.00 \%$ & $0.03 \%$ & $6.50 \%$ \\
\hline Real changes in 2014 & $17.32 \%$ & $13.00 \%$ & $0.02 \%$ & $5.00 \%$ \\
\hline
\end{tabular}

Table 10. Output of the proposed LCC prediction model of the predicted LCC between 2014 and 2030 in Cairo region.

proposed approach. Second, future changes is simulated using the real 2014 datasets. In order to check the accuracy of our approach, Table 9 compares the actual and the simulated percentages occupied by the different land cover types (urban, agriculture, water, and desert) between 1987 and 2014. According to the proposed model output, the most significant changes in this period are the transitions from agriculture and desert to urban areas (Fig. 3). Over 27 years, from 1987 to 2014, agriculture lost $12 \%$ to urban areas. Additionally, $4 \%$ of desert areas became urban between 1987 and 2014, which is equivalent to 24,687 hectares. This percentage results from the application of desert reconstruction strategies to build new communities outside the Nile Valley. The obtained results depicts that the proposed approach gives an accurate prediction with about $3.82 \%$ of error through a comparison with the real changes in Cairo region. These results confirms that the proposed LCC prediction model is reasonable to describe the LCC and the proposed approach can simulate the prediction of LCC with an acceptable accuracy. After the validation of the proposed approach, the next step is to simulate the LCC in 2030, assuming the changes between 1987 and 2014 will continue during the next 16 years. In this simulation, the LCC and input parameters acquired in 2014 are used as input to simulate the LCC in 2030. Table 10 shows the simulated changes between 2014 and 2030. There have been significant LCC where urban land covered $16.01 \%$ of simulated changes in 2014 and $21.93 \%$ in 2030 . This could be attributed to the increase in population by increased demands for residential land. The resulting effect is the decrease in desert land. From these results, we note that the desert land cover in the study area is replaced by residential land (urban land). Knowing the current and estimated urbanization situation will help decision makers to adjust and develop new plans to achieve a sustainable development of urban areas and to protect the historical locations. Figure 14 maps the simulated future changes compared with land cover maps for the years 1987 and 2014. These results indicate usefulness and applicability of the proposed approach in predicting the LCC.

\subsection{Discussion}

Current LCC prediction models do not model and propagate the uncertainties and thereby may create a false sense of certainty. The aim of this paper is to develop methods to quantify and reduce uncertainty in land cover predictions. As can be seen from Figures 10 and 11, modeling and propagating of both aleatory and epistemic uncertainty with considering correlation between model input parameters using belief function theory is very important to reduce uncertainty about LCC prediction process. Propagating uncertainty of model structure has also a significant effect on the model outcomes (Figure 13). Results in this study show that applying belief function theory for propagating uncertainty of remote sensing data improve accuracy of predicted LCC.

Understanding how uncertainties propagate through LCC prediction models enables researchers to have a clearer idea of uncertainty in LCC prediction models. This type of analysis also provides information on spatial distribution of uncertainties in the simulated LCC map to decision-makers, urban planners, and managers [74]. Several studies in other disciplines have shown that a combination of different sources of uncertainty (e.g. model parameter and model structure) increases uncertainty in the model outputs [73]. Several studies on propagation of uncertainty in LCC prediction models are limited [1] [8] [10] because they propagated the uncertainty in one level and did not separate different uncertainty sources such as model parameter and model structure. The results presented in this article show that uncertainties related to model parameter and model structure are progressively decreased (Figures 11 and 13).

Many researchers have made a valuable contribution to different topics of uncertainty in LCC prediction models; however, most did not aim to distinguish between aleatory and epistemic uncertainty in model parameter [1] [10] 


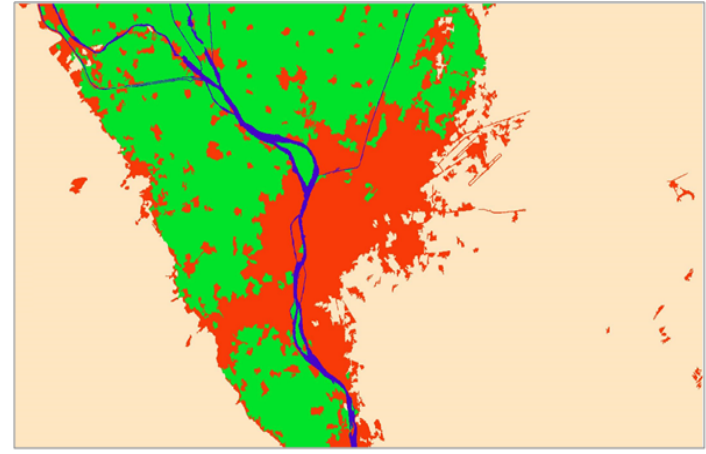

Land cover map-1987

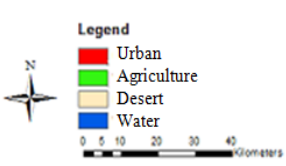

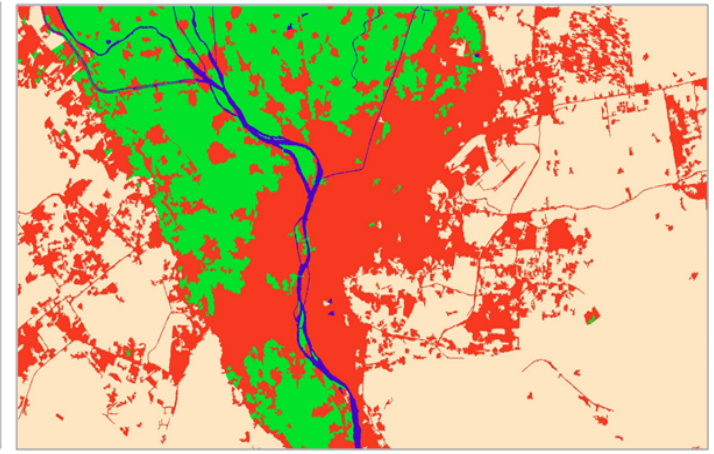

Land cover map-2014

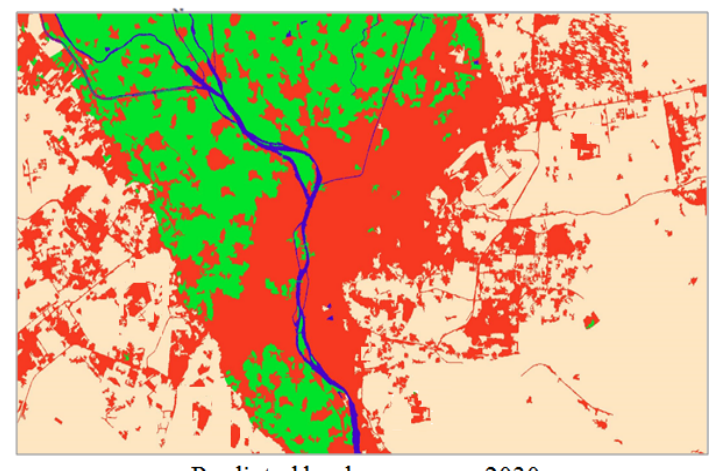

Predicted land cover map-2030

Figure 14. Comparison between the land cover maps for years 1987 and 2014 and the predicted land cover map for 2030.

[11]. Our results show that propagating both aleatoty and epistemic uncertainty in model parameter has less effect of uncertainty in LCC prediction model outputs (Figure 10) in comparison with the case when aleatory uncertainty is only considered (Figure 9).

The proposed approach is developed based on the LCC prediction model proposed by Qiang and Lam in [53]. Results on Cairo region show that the proposed approach gives an accurate prediction with about $3.82 \%$ of error compared to the real land cover changes.

The current study allows detecting urban sprawl in the Cairo region over a period of 27 years, from 1987 to 2014. Besides, an estimate of forthcoming urban changes are computed by the proposed approach. Datasets used for experimentation are composed by two Landsat images acquired on 1987 and 2014. Results show a loss of $12 \%$ of agriculture land to urban land from 1987 to 2014. Also, 4\% of desert areas were converted to urban between 1987 and 2014. The main reasons of this urban sprawl are the absence of laws against the preservation of agricultural areas and the non-application of desert reconstruction strategies, to build new urban settlements outside the Nile Valley. Hence, protection policies have to be undertaken to preserve the cultural heritage and the agricultural fields that will be negatively affected.

In this study, our objective is to determine a good tradeoff between accuracy and computational cost of LCC prediction models. For our applications to LCC prediction models, the computational cost is generally a crucial point. Thus, the parameter and structural sensitivity analysis can simplify this problem and produce more accuracy about LCC. The sensitivity analysis, which involves varying model parameters and structures and evaluating how prediction results change with these variations, has been proved to be efficient and robust to identify parameters and structures that have important effect on LCC prediction models output. However, in this study, we do not consider the sensitivity analysis.

The aim of this paper is to reduce the uncertainty of LCC prediction model to a minimum. Reducing uncertainty will help create better prediction of LCC, and help guide better science and more accurate decision-making. Understanding of the sources of uncertainty in LCC prediction process, we can make attempts to reduce uncertainty 
and to otherwise minimize the effects of uncertainty in both input parameters and model structure. In this way, we can identify the most influential uncertainty sources and return to data processing requirements to improve the remote sensing data quality. Requirements include geometric/radiometric/atmospheric corrections, data normalization, image enhancement, image segmentation, image classification and classification accuracy assessment. Uncertainty can be reduced by improved measurements and improved systems understanding, but emphasis here is on managing uncertainty through development of an appropriate accounting framework. We can motivate decreases in uncertainty through proper valuation of uncertainty and a clear understanding of the implications of uncertainty.

\section{Conclusions and perspectives}

Uncertainty propagation about LCC prediction model with both aleatory and epistemic uncertainty is presented in this paper. This paper proposes the use of a belief function theory as the uncertainty propagation method in LCC prediction model. The proposed approach is based on identification of all uncertainty sources of satellite image objects parameters and model structure of LCC prediction. Then, the uncertain input parameters are first propagated with considering mixed aleatory-epistemic uncertainty and correlation among parameters through the LCC prediction model. After that, model structure uncertainties are also propagated with belief function theory.

The results show the importance to propagate both aleatory and epistemic uncertainty and to consider correlation among input parameters through LCC prediction model. Proposed approach studied the changes prediction of land cover in Cairo region, Egypt of next 16 years (2030) using multi-temporal Landsat TM5 satellite images in 1987 and 2014. Results indicated that the urban land covered $16.01 \%$ of simulated changes in 2014 and $21.93 \%$ in 2030. From these results, it can be found the replacing the desert and agriculture land cover in the study area by residential land (urban land).

The results show that the LCC prediction model using 16 input parameters representing both spectral, texture, shape, vegetation and climate characteristics, could simulate the LCC changes with satisfactory degrees of accuracy. This study has also demonstrated the usefulness of the propagating uncertainty of input parameters and model structure of LCC prediction in providing land cover maps and change information, which are very valuable for planning and management. More work, however, is needed to understand how to reduce the computational cost in our proposed approach. LCC prediction model with a large number of uncertain input parameters is more complex. To optimize, it is important to study the sensitivity of input parameters and also the sensitivity of model structure.

\section{Acknowledgment}

The authors would like to thank the USGS for providing the the Landsat data. This work was carried out in RIADI laboratory (ENSI, Manouba, Tunisia) and ITI Department (TELECOM-Bretagne, Brest, France).

\section{References}

[1] W. Boulila, A. Bouatay, I.R. Farah, A Probabilistic Collocation Method for the Imperfection Propagation: Application to Land Cover Change Prediction, Journal of Multimedia Processing and Technologies 5(1) (2014) 12-32.

[2] M. Crosettoa, J.A.M. Ruiz, B. Crippac, Uncertainty propagation in models driven by remotely sensed data, Remote Sensing of Environment 76(3) (2001) 373-385.

[3] K. Cockx, T. Van de Voorde, F. Canters, Quantifying uncertainty in remote sensing-based urban land-use mapping, International Journal of Applied Earth Observation and Geoinformation 31 (2014) 154-166.

[4] M.V. Oijen, A. Thomson, Toward Bayesian uncertainty quantification for forestry models used in the United Kingdom Green house Gas Inventory for land use, land use change, and forestry, Climatic Change 103 (2010) 55-67.

[5] F.O. Hoffman, J.S. Hammonds, Propagation of uncertainty in risk assessment: the need to distinguish between uncertainty due to lack of knowledge and uncertainty due to variability, Risk Analysis 14(5) (1994) 707-712.

[6] A. Ferchichi, W. Boulila, I.R. Farah, An intelligent possibilistic approach to reduce the effect of the imperfection propagation on land cover change prediction, International Conference on Computational Collective Intelligence 9330 (2015) 520-529.

[7] Y. Yanab, E. Trouvea, V. Pinelb, G. Maurisa, E. Pathierc, S. Galicheta, Fusion of D-InSAR and sub-pixel image correlation measurements for coseismic displacement field estimation: Application to the Kashmir earthquake (2005), International Journal of Image and Data Fusion 3(1) (2012) 71-92 
[8] A. P. Jacquin, Possibilistic uncertainty analysis of a conceptual model of snowmelt runoff, Hydrol. Earth Syst. Sci. 14 (2010) $1681-1695$.

[9] L. Hubert-Moy, S. Corgne, G. Mercier, B. Solaiman, Land Use and Land Cover Change Prediction with the Theory of Evidence : A Case Study in an Intensive Agricultural Region of France, Proceedings of the Fifth International Conference on Information Fusion 1 (2002) $114-121$.

[10] F. Silvestro, S. Gabellani, R. Rudari, F. Delogu, P. Laiolo, G. Boni, Uncertainty reduction and parameter estimation of a distributed hydrological model with ground and remote-sensing data, Hydrol. Earth Syst. Sci. 19 (2015) 1727-1751.

[11] R. Liu, J. Sun, J. Wang, X. Li, Study of remote sensing based parameter uncertainty in production Efficiency Models, IEEE International Geoscience and Remote Sensing Symposium (2010) 3303-3306.

[12] A. Ferchichi, W. Boulila, I.R. Farah, Parameter and structural model imperfection propagation using evidence theory in land cover change prediction, International Conference Image Processing, Applications and Systems (2014) 1-6

[13] Z.Q. Gao, O. Dennis, The temporal and spatial relationship between NDVI and climatological parameters in Colorado, Journal of Geographical Sciences 11(4) (2001) 411-419.

[14] M. A. Pea, Relationships between remotely sensed surface parameters associated with the urban heat sink formation in Santiago, Chile, International Journal of Remote Sensing 29(15) (2008) 4385-4404.

[15] J.O. Sexton, P. Noojipady, A. Anand, X.P. Song, S. McMahon, C. Huang, M. Feng, S. Channan, J.R. Townshend, A model for the propagation of uncertainty from continuous estimates of tree cover to categorical forest cover and change, Remote Sensing of Environment 156 (2015) $418-$ 425.

[16] W. Z. Shi, M. Ehlers, Determining uncertainties and their propagation in dynamic change detection based on classified remotely-sensed images, International Journal of Remote Sensing 17(14) (1996) 2729-2741.

[17] J. Beekhuizen, G.B.M. Heuvelink, I. Reusen, J. Biesemans, Uncertainty Propagation Analysis of the airborne hyperspectral data processing chain, First Workshop on Hyperspectral Image and Signal Processing: Evolution in Remote Sensing (2009) 1-4.

[18] K.L. Larson, D.D. White, P.Gober, A.Wutich, Decision-Making under Uncertainty for Water Sustainability and Urban Climate Change Adaptation, Sustainability 7(11) (2015) 14761-14784.

[19] D. Dubois and H. Prade, Formal representations of uncertainty, Decision-Making Process: Concepts and Methods. London, U.K.: ISTE and Wiley, ch.3 (2010) 85-156.

[20] W.F. Caselton, W.Luo, Decision making with imprecise probabilities: Dempster-Shafer Theory and application, water resources research, 28(12) (1992) 3071-3083.

[21] X. Zhao, A. Stein, X. Chen, Application of random sets to model uncertainties of natural entities extracted from remote sensing images, Stochastic Environmental Research and Risk Assessment 24(5) (2009) 713-723.

[22] S. L. Hgarat-Mascle, I. Bloch, D. Vidal-Madjar, Application of Dempster-Shafer Evidence Theory to Unsupervised Classification in Multisource Remote Sensing, IEEE Transactions on Geoscience and Remote Sensing 35(4) (1997) 1018-1031.

[23] Z. Liu, J. Dezert, G. Mercier, Q.Pan, Dynamic Evidential Reasoning for Change Detection in Remote Sensing Images, IEEE Transactions on Geoscience and Remote Sensing, 50(5) (2012) 1955-1967.

[24] D. Gomez, M. Javier, Fuzzy sets in remote sensing classification. Soft Computing 12(3) (2008) 243-249.

[25] F.J. De Souza, M.L.F. Velloso, O.L.H. Fonseca, Change-detection of land cover using fuzzy sets and remotely sensed data, IEEE International Geoscience and Remote Sensing Symposium 6 (2002) 3381-3383.

[26] S. Foucher, M. Germain, J.M. Boucher, G.B. Bni, Multisource Classification Using ICM and Dempster-Shafer Theory, IEEE Transactions on Instrumentation and Measurement 51(2) (2002) 277-281.

[27] A. Sarkar, A. Banerjee, N. Banerjee, S. Brahma, B. Kartikeyan, M. Chakraborty, K. L. Majumder, Landcover Classification in MRF Context Using Dempster-Shafer Fusion for Multisensor Imagery, IEEE Transactions on Image Processing 14(5) (2005) 634-645.

[28] V. Saeidi, B. Pradhan, M.O. Idrees, Z. Abd Latif, Fusion of Airborne LiDAR With Multispectral SPOT 5 Image for Enhancement of Feature Extraction Using Dempster-Shafer Theory, IEEE Transactions on Geoscience and Remote Sensing 52(10) (2014) 6017-6025.

[29] F. Leduc, B. Solaiman, F. Cavayas, Combination of fuzzy sets and Dempster-Shafer theories in forest map updating using multispectral data, Proc. SPIE Sensor Fusion: Architectures, Algorithms, and Applications V 4385 (2001) 323-334.

[30] A.A.A. Al-sharif, B. Pradhan, Spatio-temporal Prediction of Urban Expansion Using Bivariate Statistical Models: Assessment of the Efficacy of Evidential Belief Functions and Frequency Ratio Models, Applied Spatial Analysis and Policy (2015) 1-19.

[31] E. Kriegler, H. Held, Utilizing belief function for the estimation of future climate change, International Journal of Approximate Reasoning 39 (2005) 185-209.

[32] A. Bendjebbour, Y. Delignon, L.Fouque, V. Samson, W. Pieczynski, Multisensor Image Segmentation Using Dempster-Shafer Fusion in Markov Fields Context, IEEE Transactions on Geoscience and Remote Sensing 39(8) (2001) 1789-1798.

[33] F. Salzenstein, A.O. Boudraa, Iterative estimation of Dempster-Shafer's basic probability assignment: application to multisensor image segmentation, Opt. Eng. 43(6) (2004) 1293-1299.

[34] J.K. Lein, Applying evidential reasoning methods to agricultural land cover classification, International Journal of Remote Sensing 24(21) (2003) 4161-4180.

[35] L. Cayuela, J.D. Golicher, J.S. Rey, J.M.R. Benayas, Classification of a complex landscape using Dempster-Shafer theory of evidence, International Journal of Remote Sensing 27(10) (2006) 1951-1971.

[36] S.Chitroub, A.Houacine, B.Sansal, Evidential reasoning-based classification method for remotely sensed images, Proc. SPIE Image and Signal Processing for Remote Sensing VII 4541 (2002) 340-351.

[37] A. Laha, N.R. Pal, J. Das, Land cover classification using fuzzy rules and aggregation of contextual information through evidence theory, IEEE Transactions on Geoscience and Remote Sensing 44(6) (2006) 1633-1641.

[38] M.N. Jebur, B. Pradhan, M.S. Tehrany, Manifestation of LiDAR-Derived Parameters in the Spatial Prediction of Landslides Using Novel Ensemble Evidential Belief Functions and Support Vector Machine Models in GIS, IEEE Journal of Selected Topics in Applied Earth Observations and Remote Sensing 8(2)(2015) 674-690.

[39] N.B. Abdallah, N. Mouhous-Voyneau, T. Denoeux, Using Dempster-Shafer Theory to model uncertainty in climate change and environmental impact assessments, International Conference on Information Fusion (2013) 2117-2124.

[40] A. Zargar, R.Sadiq, G. Naser, A.M. ASCE, F.I. Khan, N.N. Neumann, Dempster-Shafer Theory for Handling Conflict in Hydrological Data: 
Case of Snow Water Equivalent, Journal of Computing in Civil Engineering 26(3) (2012)434-447.

[41] A.P. Dempster, Upper and lower probabilities induced by a multivalued mapping, Annals of Mathematical Statistics 38 (1967) $325-339$.

[42] G.A. Shafer, Mathematical theory of evidence, Princeton: Princeton University Press, 1976.

[43] K. Sutton, W. Fahmi, Cairo's urban growth and strategic master plans in the light of Egypt's 1996 population census results. Cities, 18(3) (2001) 135-149.

[44] Z.Y. Yin, D.J. Stewart, S. Bullard, J.T. Maclachlan, Changes in urban built-up surface and population distribution patterns during 1986-1999: A case study of Cairo, Egypt. Comput. Environ. Urban Syst. 29 (2005) 595-616.

[45] E. Mohamed, Analysis of urban growth at Cairo, Egypt using remote sensing and GIS. Nat. Sci. 4 (2012).

[46] V.E. de Noronha, M. Caetano, P. Nijkamp, Trapped between antiquity and urbanism-A multi-criteria assessment model of the Greater Cairo Metropolitan Area. J. Land Use Sci. 6 (2011) 283-299.

[47] Jr.F. Ballestores, Z. Qiu, B.N. Nedorezova, L.V. Nedorezov, A. Ferrarini, A. Ramathilaga, M. Ackah, An integrated parcel-based land use change model using cellular automata and decision tree, Proceedings of the International Academy of Ecology and Environmental Sciences 2(2) (2012) 53-69.

[48] B.S. Razavi, Predicting the Trend of Land Use Changes Using Artificial Neural Network and Markov Chain Model (Case Study: Kermanshah City), Research Journal of Environmental and Earth Sciences 6(4) (2014) 215-226.

[49] A. Tayyebi, P.C. Perry, A.H. Tayyebi, Predicting the expansion of an urban boundary using spatial logistic regression and hybrid rastervector routines with remote sensing and GIS. International Journal of Geographical Information Science 28(4) (2013) 1-21.

[50] C.G. Ralha, C.G. Abreu, C.G. Coelho, A. Zaghetto, B. Macchiavello, R.B. Machado, A multi-agent model system for land-use change simulation, Environmental Modeling and Software 42 (2013) 30-46.

[51] W. Boulila, I.R. Farah, K.S. Ettabaa, B. Solaiman, H. Ben Ghzala, A data mining based approach to predict Spatio-temporal changes in satellite images, International Journal of Applied Earth Observation and Geoinformation 13(3) (2011) 386-395.

[52] X. Li, A.G.O. Yeh, Neural-network-based cellular automata for simulating multiple land use changes using GIS, International Journal of Geographical Information Science 16(4) (2002) 323-343.

[53] Y. Qiang, N.S.N. Lam, Modeling land use and land cover changes in a vulnerable coastal region using artificial neural networks and cellular automata, Environ Monit Assess 187(57) (2015) 1-16.

[54] K. Navulur, Multispectral image analysis using the object-oriented paradigm. CRC Press, Taylor and Francis Group (2007).

[55] F. Bonn, G. Rochon, Accurate Remote Sensing, thematic Application, Quebec University, Quebec, 1996.

[56] R.A. Peters, A new algorithm for image noise reduction using mathematical morphology, IEEE Transactions on Image Processing 4(5) (1995) 554-568.

[57] G.C. Hulley, C.G. Hughes, S.J. Hook, Quantifying uncertainties in land surface temperature and emissivity retrievals from ASTER and MODIS thermal infrared data, Journal of Geophysical Research 117(D23) (2012) 1-18.

[58] M. Pesaresi, J.A. Benediktsson, A New Approach for the Morphological Segmentation of High-Resolution Satellite Imagery, IEEE Transactions on Geoscience and Remote Sensing 39(2) (2001) 309-320.

[59] T. Miura, A.R. Huete, H. Yoshioka, Evaluation of Sensor Calibration Uncertainties on Vegetation Indices for MODIS, IEEE Transactions on Geoscience and Remote Sensing 38(3) (2000) 1399-1409.

[60] J.N. Hird, G.J. McDermid, Noise reduction of NDVI time series: An empirical comparison of selected techniques, Remote Sensing of Environment 113(1) (2009) 248258.

[61] J.C. Jimenez-Munoz, J.A. Sobrino, Error sources on the land surface temperature retrieved from thermal infrared single channel remote sensing data, International Journal of Remote Sensing 27(5) (2006) 999-1014.

[62] V. Atanassov, G. Jelev, L. Kraleva, Some Peculiarities of the Preprocessing of Spectral Data and Images, Journal of Shipping and Ocean Engineering 3 (2013) 55-60.

[63] E.L. Droguett, A. Mosleh, Integrated treatment of model and parameter uncertainties through a Bayesian approach, Journal of Risk and Reliability 227(1) (2012) 41-54.

[64] Batty, M. Urban modeling, In International Encyclopedia of Human Geography, Elsevier: Oxford, UK, (2009) 51-58.

[65] P.H. Verburg, P.P. Schot, M.J. Dijst, A. Veldkamp, Land use change modelling: Current practice and research priorities, GeoJournal 61 (2004) 309-324.

[66] S. Ferson, V. Kreinovich, L. Ginzburg, D. Myers, K. Sentz, Constructing probability boxes and DempsterShafer structures, Technical report. Sandia National Laboratories (2003).

[67] LH. Miller, Table of percentage points of Kolmogorov statistics, Journal of the American Statistical Association 51 (1956) $111-121$.

[68] H. Lilliefors, On the KolmogorovSmirnov test for normality with mean and variance unknown, Journal of the American Statistical Association 62 (1967) 399-402.

[69] Y.J. Luo, Z. Kang, Z. Luo, L. Alex, Continuum topology optimization with nonprobabilistic reliability constraints based on multi-ellipsoid convex model, Journal of Structural and Multidisciplinary Optimization 39(3) (2008) 297-310.

[70] L. Bain, M. Engelhardt, Introduction to Probability and Mathematical Statistic, 2nd ed., Duxbury, Pacific Grove, CA, 1991.

[71] M.S. Balch, Mathematical Foundations for a Theory of Confidence Structures, International Journal of Approximate Reasoning 53(7) (2012) 1003-1019.

[72] C. Jiang, B. Wang, Z.R. Li, X. Han, D.J. Yu, An evidence-theory model considering dependence among parameters and its application in structural reliability analysis, Engineering Structures 57 (2013) 12-22.

[73] E.L. Droguett, A. Mosleh, Integrated treatment of model and parameter uncertainties through a Bayesian approach, Proceedings of the Institution of Mechanical Engineers, Part O: Journal of Risk and Reliability 227 (2012) 41-54.

[74] J.A. Verstegen, D. Karssenberg, F. van der Hilst, A.P.C. Faaij, Detecting systemic change in a land use system by Bayesian data assimilation, Environmental Modelling and Software 75 (2016) 424-438. 


\section{Graphical abstract}

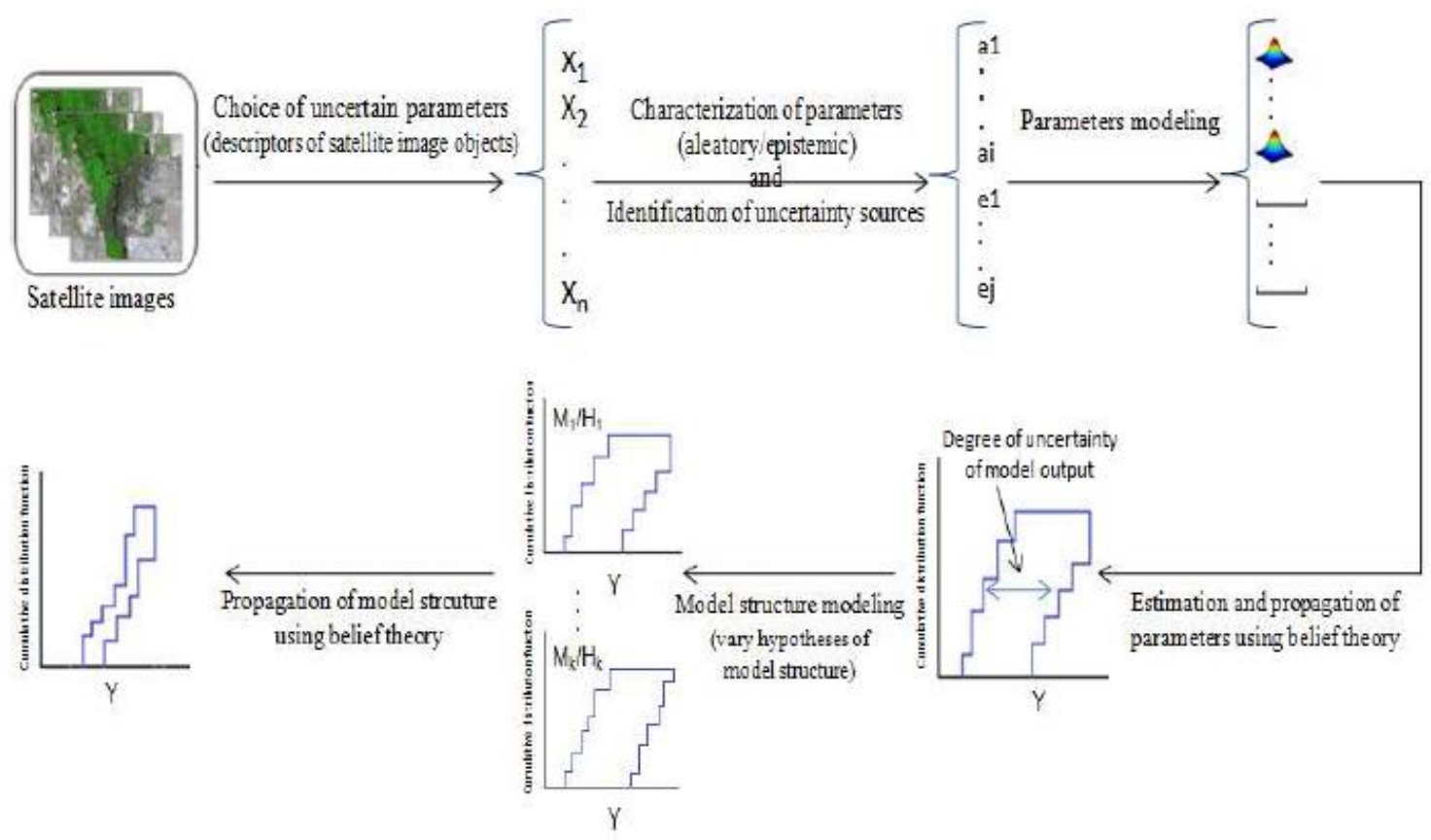

